\title{
The role of inflammation in epileptogenesis
}

\author{
Fanwei Meng and Lifen Yao* (iD
}

\begin{abstract}
Epilepsy is a chronic neurological disorder that has an extensive impact on a patient's life. Accumulating evidence has suggested that inflammation participates in the progression of spontaneous and recurrent seizures. Proconvulsant incidences can stimulate immune cells, augment the release of pro-inflammatory cytokines, elicit neuronal excitation as well as blood-brain barrier (BBB) dysfunction, and finally trigger the generation or recurrence of seizures. Understanding the pathogenic roles of inflammatory mediators, including inflammatory cytokines, cells, and BBB, in epileptogenesis will be beneficial for the treatment of epilepsy. In this systematic review, we performed a literature search on the PubMed database using the following keywords: "epilepsy" or "seizures" or "epileptogenesis", and "immunity" or "inflammation" or "neuroinflammation" or "damage-associated molecular patterns" or "cytokines" or "chemokines" or "adhesion molecules" or "microglia" or "astrocyte" or "blood-brain barrier". We summarized the classic inflammatory mediators and their pathogenic effects in the pathogenesis of epilepsy, based on the most recent findings from both human and animal model studies.
\end{abstract}

Keywords: Epileptogenesis, Inflammatory mediators, Blood-brain barrier breakdown, Microglia, Astrocyte, Receptors

\section{Background}

Epilepsy is a neurological disorder, which is clinically defined as having at least two unprovoked seizures with an interval of more than $24 \mathrm{~h}$; one unprovoked (or reflex) seizure whose recurrence risk exceeds $60 \%$ in the next ten years; or a confirmed epilepsy syndrome [1]. Almost 70 million people worldwide suffer from epilepsy [2], $30 \%$ of whom have failed to respond to medical management [3]. The causes of epilepsy can be divided into six categories: genetic, structural, metabolic, infectious, immune-associated, and unknown [4].

Although the precise and integrated mechanisms of epilepsy remain to be clarified, recent evidence has shown the involvement of changes in the neuronal ligand and voltage-gated ion channels, imbalance between excitatory and inhibitory neurotransmitters, oxidative stress, mitochondrial dysfunction, inflammatory and immune lesions, microglia and astrocyte activation, and blood-brain barrier (BBB) breakdown. Studies on epilepsy using both in vivo and in vitro experiments have verified the indispensable roles of inflammatory

\footnotetext{
*Correspondence: yaolifen_2015@sina.com

Department of Neurology, The First Affiliated Hospital of Harbin Medical University, Harbin 150001, China
}

mediators in epileptogenesis, including inflammatory molecules and cells, and BBB destruction. Proconvulsive events can initiate inflammatory processes through high mobility group protein 1 (HMGB1, also a damage-associated molecular pattern[DAMP]) and interleukin-1 $\beta$ (IL-1 $\beta$ ), which are released from activated glial cells and stimulated neurons after pro-convulsive events and then bind to Toll-like receptors (TLRs) and IL-1 receptor (IL-1R), respectively. The inflammatory events will further result in the production and release of other immune molecules by activated astrocytes and microglia, thereby amplifying the downstream inflammatory cascades. In neuroinflammation, astrocytes act as the main component of $\mathrm{BBB}$, as well as an essential source and target of inflammatory mediators [5]. Microglial cells are the resident macrophages of the central nervous system (CNS), serving on the first line of immune defense in the brain [6]. The ongoing inflammatory state could cause BBB destruction, through which the peripheral immune components can participate in epileptogenesis. The up-regulated release of these inflammatory mediators would cause aberrant neuronal hyper-excitability by increasing the permeability of glutamatergic neurons to the calcium ion $\left(\mathrm{Ca}^{2+}\right)$ [7]. Besides, 
subsequent changes in energy and glutamate metabolism after the activation of astrocytes will further cause neuronal injury and over-excitation [8]. Most of these inflammatory responses tend to have long-lasting effects, finally triggering the recurrence of seizures. The overall relationship between inflammatory mediators and epileptogenesis is shown in Fig. 1.

Here, we systematically reviewed studies that investigated the roles of inflammation in epilepsy using both in vivo and in vitro experiments.

\section{Methods}

The literature search was performed on the PubMed database (https://www.ncbi.nlm.nih.gov/), using the following keywords: "epilepsy" or "seizures" or "epileptogenesis", and "immunity" or "inflammation" or "neuroinflammation" or "damage-associated molecular patterns" or "cytokines" or "chemokines" or "adhesion molecules" or "microglia" or "astrocyte" or "blood-brain barrier". All the inflammatory mediators and pathways involved in the pathogenesis of epilepsy as reported in these studies are summarized in the following sections.

\section{Inflammatory mediators}

DAMPs: potential initiators of epileptogenesis

Infection can increase the susceptibility to seizures. However, seizures always occur without infection (such as hypoxia and brain insults, etc.). DAMPs are a group of endogenous molecules, including heat-shock protein (HSP), hyaluronan, nucleic acid, heparan sulfate, surfactant protein-A, fibrinogen, adenosine triphosphate (ATP) and HMGB1 $[9,10]$. DAMPs can be released by neurons following pathogenic events and recognized by pattern recognition receptors (PRRs), thus initiating inflammatory and immune responses in the absence of infection. Both immune cells (microglia) and non-immune cells (such as astrocytes and neurons) in the CNS can express PRRs for DAMPs. The interactions between

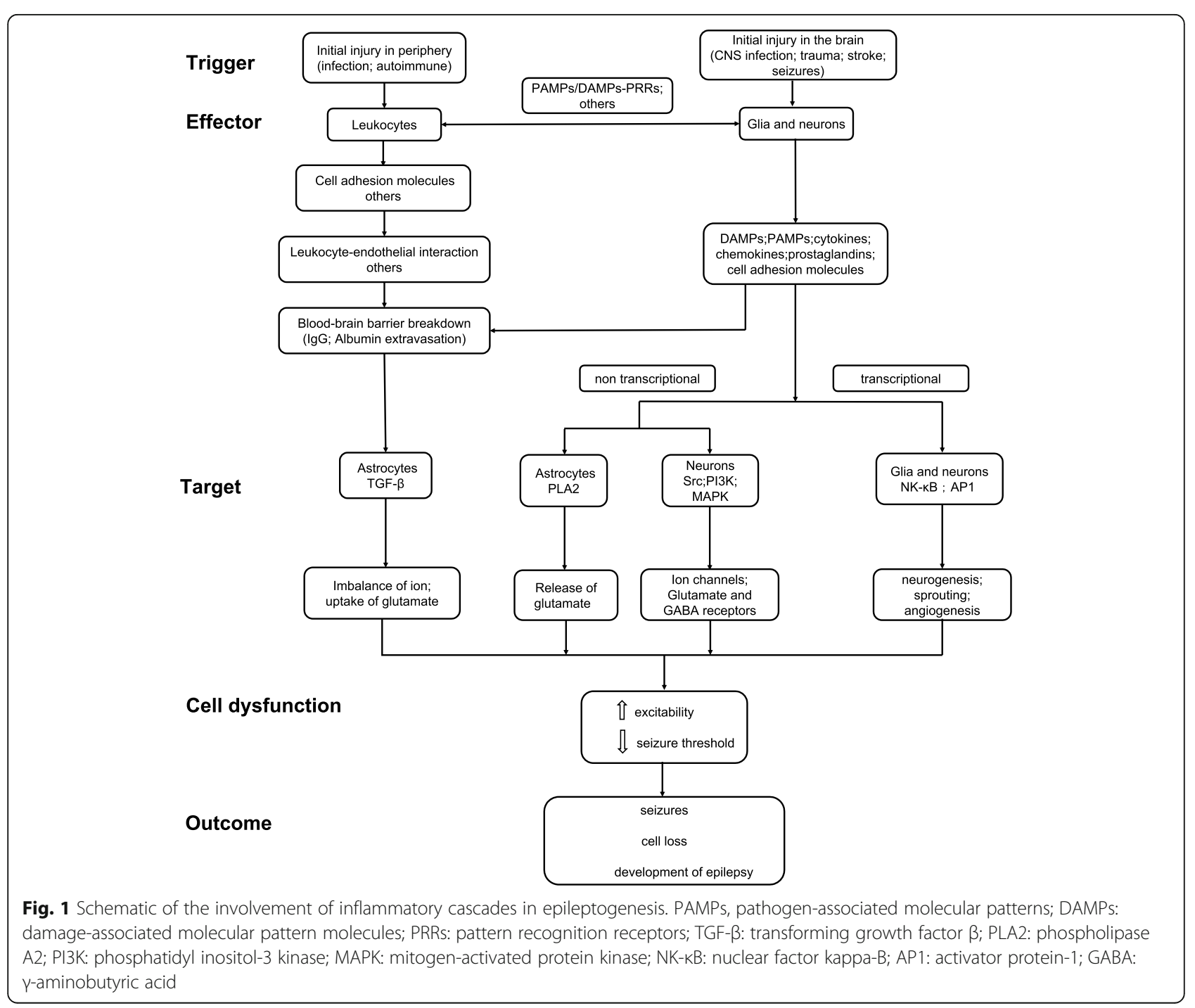


DAMPs and PRRs result in abnormal synaptic transmission and neuronal hyper-excitability [11].

\section{HMGB1 and the TLR4/RAGE pathway}

HMGB1 is one of the typical DAMPs, also known as amphoterin. It is a non-histone component of chromatin, which is ubiquitously expressed in the cell nucleus. HMGB1 has received increasing attention due to its role in epilepsy. Under physiological conditions, HMGB1 usually participates in the chromatin binding process of distinct site-specific transcription factors, such as HOX proteins, recombination activating gene $1 / 2$ recombinase, and the tumor suppressor gene p53 [12]. Under pathological circumstances, HMGB1 can be released by damaged, necrotic, and apoptotic cells [13]. Moreover, specific cells such as endothelial cells, glial cells, and neurons might secrete HMGB1 upon stimulation by cytokines, hypoxia, seizures, etc. It is well-known that ATP is closely associated with the release of HMGB1. Cells under pathological conditions can release ATP into extracellular space. The rapid increase of ATP can lead to the P2X7R (purinergic ligand-gated ion channel 7)mediated activation of NOD-like receptor protein 3 (NLRP3) inflammasome, further promoting the release of HMGB1 [14]. Despite extensive research on HMGB1, the molecular mechanisms underlying HMGB1 release at pathological circumstances have not yet been fully elucidated. HMGB1 plays pro-inflammatory roles by activating two primary PRRs: the receptor for advanced glycation end-products (RAGE) and TLR4. However, the RAGE may not have a prominent role as TLR4 in epileptogenesis. A previous study using mouse models of kainic acid (KA)-induced mesial temporal lobe epilepsy (MTLE) shows that both TLR4 knockout and RAGE knockout mice reduce seizure activities after the injection of KA, and the reduction of seizure activity is more significant in the context of TLR4 knockout [15]. After binding to HMGB1, TLR4 leads to the activation of mediator myeloid differentiation factor 88 (MyD88), nuclear factor-kappa B (NF-kB), AP-1, or interferonregulatory factor 3 [16], while RAGE causes activation of the mitogen-activated protein kinase (MAPK) signaling cascades, and induces the release and activation of NF$\kappa B$ [17]. Therefore, the NK- $\kappa B$ pathway may be a common downstream target of both TLR4 and RAGE signaling pathways. All of these transcription factors will contribute to the expression of pro-inflammatory mediators and the activation of immune cascades. In addition, the activated TLR4 can enhance $\mathrm{Ca}^{2+}$ influx in neurons mediated by the N-methyl-D-aspartic acid (NMDA) receptor (NMDAR), a process that involves Src kinases and nSmase [18]. The TLR4 may also participate in the non-NMDA glutamatergic currents [19]. Whether similar patterns are employed by activated RAGE to trigger neuronal hyper-excitability requires further investigation.

A more recent study shows that in status epilepticus (SE) rats induced by lithium-pilocarpine, glycyrrhizin has neuroprotective effects by inhibiting HMGB1 and maintaining the integrity of $\mathrm{BBB}$, which indicates that HMGB1 may be one of the primary triggers of $\mathrm{BBB}$ breakdown [20]. It has been shown earlier that in neurological diseases, HMGB1 can compromise the integrity of BBB via either TLR4 or RAGE [21, 22]. HMGB1 can also cause drug resistance in patients with epilepsy by increasing TLR4- or RAGE-mediated P-gp expression (an efflux transporter protein) in the primary endothelial barrier of the BBB [23]. Moreover, pharmacological inhibition of HMGB1 not only decreases the frequency and duration of KA-induced seizures but also delays the onset of seizures [24], which verifies the important role of HMGB1 in the process of epilepsy generation.

\section{ATP/P2X7R pathway}

Apart from being a molecular energy unit for numerous metabolic processes, ATP also serves as a neurotransmitter in the CNS and peripheral nervous system, either solely stored in synaptic vesicles and granules or stored with other neurotransmitters such as $\gamma$-aminobutyric acid (GABA) and glutamate [25]. The extracellular concentration of ATP is relatively low under normal conditions but will increase rapidly in response to insults, such as trauma, ischemia, hypoxia, and abnormal neuronal activities [26], via pannexins or connexin hemichannels [27]. The dramatic efflux of ATP then initiates the stress or damage response system. A portion of ATP can be metabolized by ectonucleotidases into different products, including adenosine 50-diphosphate (ADP) and adenosine, which also participate in the inflammatory pathways and ultimately trigger epileptic seizures after release [28]. The extracellular ATP can activate purinergic 2 receptors (P2Rs), which are expressed on almost all types of cells in the CNS. P2Rs are implicated in many important biological processes, such as cell proliferation, differentiation, excitement, and inflammation [29]. P2Rs can be divided into the ionotropic type (P2XRs) and the metabolic type (P2YRs) [30]. Unlike P2YRs that can recognize almost all types of nucleotides (including ATP, ADP, UDP, and UTP) [31], most P2XRs only target ATP.

Among the seven subfamilies of P2XRs (P2X1RP2X7R), the P2X7Rs have received much attention in the research of epilepsy and neuroinflammation. P2X7Rs are mainly expressed on microglia, oligodendrocytes, and ependymal cells and can also be expressed by astrocytes and neurons [32]. In the coriaria lactone-induced SE rat model, pre-treatment with P2X7R antagonist A438079 significantly reduces the over-expression of IL- 
$1 \beta$ and IL-6, while treatment with the P2X7R agonist BzATP increases their expression [33]. As a DAMP, ATP exerts effects mainly by binding to P2X7Rs, which further activates inflammasome and caspase-1, mainly by increasing the permeability of plasma membrane to potassium ions $\left(\mathrm{K}^{+}\right)$and promotes cytokines release. The NALP3 inflammasome induces caspase-1-mediated cleavage of precursors of some pro-ictogenic cytokines into the active form (such as IL-1 $\beta$ and IL-18). Then the loading of the inflammasome complex into secretory lysosomes triggers the release of active cytokines. The ATP-P2X7Rs axis is also involved in the up-regulation of reactive oxygen species (ROS) mainly in microglia, and the release of prostaglandin E2 (PGE2) [32, 34, 35]. Prolonged activation of the ATP-P2X7Rs pathway will trigger microgliosis and astrogliosis. Astrogliosis itself will induce extracellular ionic imbalance, influence neurotransmitter reuptake, and trigger the $\mathrm{BBB}$ breakdown and release of pro-inflammatory cytokines and DAMPs (including ATP and adenosine) [32]. The activated microglia also release an increasing amount of cytokines as well [32]. Moreover, the activation of IL-1 $\beta$ subsequently leads to the production of matrix metalloproteinase-9 (MMP-9), which affects the tight junction proteins of $\mathrm{BBB}$ and thus the integrity of $\mathrm{BBB}$ [36]. Studies using in vitro models of $\mathrm{BBB}$ disruption induced by BzATP (a photoreactive ATP agonist) reveals that A438079 (a selective P2X7Rs antagonist), IL-1R antagonist (IL-1RA) and batimastat (an MMP antagonist) all attenuate the paracellular permeability; A438079 alleviates the increase of IL-1 $\beta$ and MMP-9, and IL-1RA mitigates the induction of MMP by BzATP [36]. All these findings provide evidence for immune mechanisms of epileptogenesis.

In addition, P2X7Rs regulate gliotransmitter release. P2X7Rs may increase the exocytosis ratio of glutamate/ GABA in a $\mathrm{Ca}^{2+}$-dependent manner in rat cortical nerve terminals, which contributes to the development of seizures [37].

\section{Cytokines: multiple players in epileptogenesis}

Cytokines are a broad array of signaling proteins produced primarily by peripheral immune cells (monocytes, macrophages, leukocytes, endothelial and perivascular cells) and CNS cells (microglia, astrocytes, and neurons), including IL, lymphokines, chemokines, interferons, transforming growth factors (TGF), tumor necrosis factors (TNF), etc. The concentrations of cytokines in the brain are relatively low under normal conditions. However, they can be increased upon the incidence of epileptogenic events, such as infection, stroke, hypoxia, tissue injury, and seizures [38]. After the epileptogenic insults or the first seizure, the expression of cytokines and their cognate receptors is increased. The first secretory wave of cytokines could trigger and support the second release wave of inflammatory mediators of glial cells or neurons, and amplify the inflammatory downstream cascades, resulting in neuronal overexcitation (Fig. 2). The essential cytokines involved in the pathogenic mechanisms of neuronal hyper-excitation and seizures are summarized below.

\section{The IL-1 $\beta /$ IL-1R1 pathway}

During the development of epilepsy, IL-1 $\beta$ can be produced by activated microglia as well as astrocytes [39]. Recent evidence further indicates that neurons can also secrete IL-1 $\beta$. The IL-1 $\beta /$ IL-1R1 signaling is essential for the initiation of inflammatory responses during epilepsy incidence. The activation of IL-1R1 by IL- $1 \beta$ facilitates the expression of several downstream mediators including IL-6, TNF $\alpha$, and cyclooxygenase-2 (COX-2) through an NF-kB-dependent transcriptional pathway. IL-1 $\beta$ can also decrease the expression of inhibitors of pro-inflammatory mediators. Recently, IL-1 $\beta$ has been shown to down-regulate the expression of complement factor $\mathrm{H}(\mathrm{CFH}$, an inhibitor of the alternative pathways of complement cascade) as a feedback in the hippocampus of a chronic temporal lobe epilepsy (TLE) rat model [40]. In addition to aggravating immune responses, the IL-1 $\beta /$ IL-1R1 pathway can also disturb the neuronal excitatory state by directly promoting the neuronal network hyper-excitation in a relatively fast, nontranscriptional way. The IL- $1 \beta-I L-1 R$ axis induces phosphorylation of the NR2B subunit of the NMDAR, which is mediated by the Src-family tyrosine kinase. The phosphorylation of NMDAR will then increase the $\mathrm{Ca}^{2+}$ influx in neurons [41]. In hippocampal neurons, IL-1 $\beta$ could increase synaptophysin (SYN) expression by stimulating the phosphoinositide 3-kinase (PI3K)/ protein kinase $\mathrm{B}$ (AKT) /mammalian target of rapamycin (mTOR) pathway, and SYN has been found to be related to recurrent seizures in a lithium-pilocarpine-induced MTLE rat model [42]. On the other hand, the activation of IL-1R1 may result in the fast onset of MyD88dependent, ceramide-mediated activation of the Srcfamily tyrosine kinases in the preoptic area/anterior hypothalamus, which can influence the A-type $\mathrm{K}^{+}$currents in neurons and consequently reduce the synaptic release of GABA [39]. The imbalance between glutamate and GABA induced by IL-1 $\beta$ serves as the foundation for seizure development. IL-1 $\beta$ has also been proved to contribute to BBB breakdown, which may be involved in the increase of MMP-9 [36, 43]. Pharmacological evidence shows that blockade of the IL- $1 \beta$-mediated pathway by an IL-1 $\beta$ receptor antagonist anakinra and an anti-inflammatory agent VX-765 (a specific non-peptide inhibitor of IL-1 $\beta$ cleavage and release) provides neuroprotection in an SE rat model [44]. The anti-convulsive 


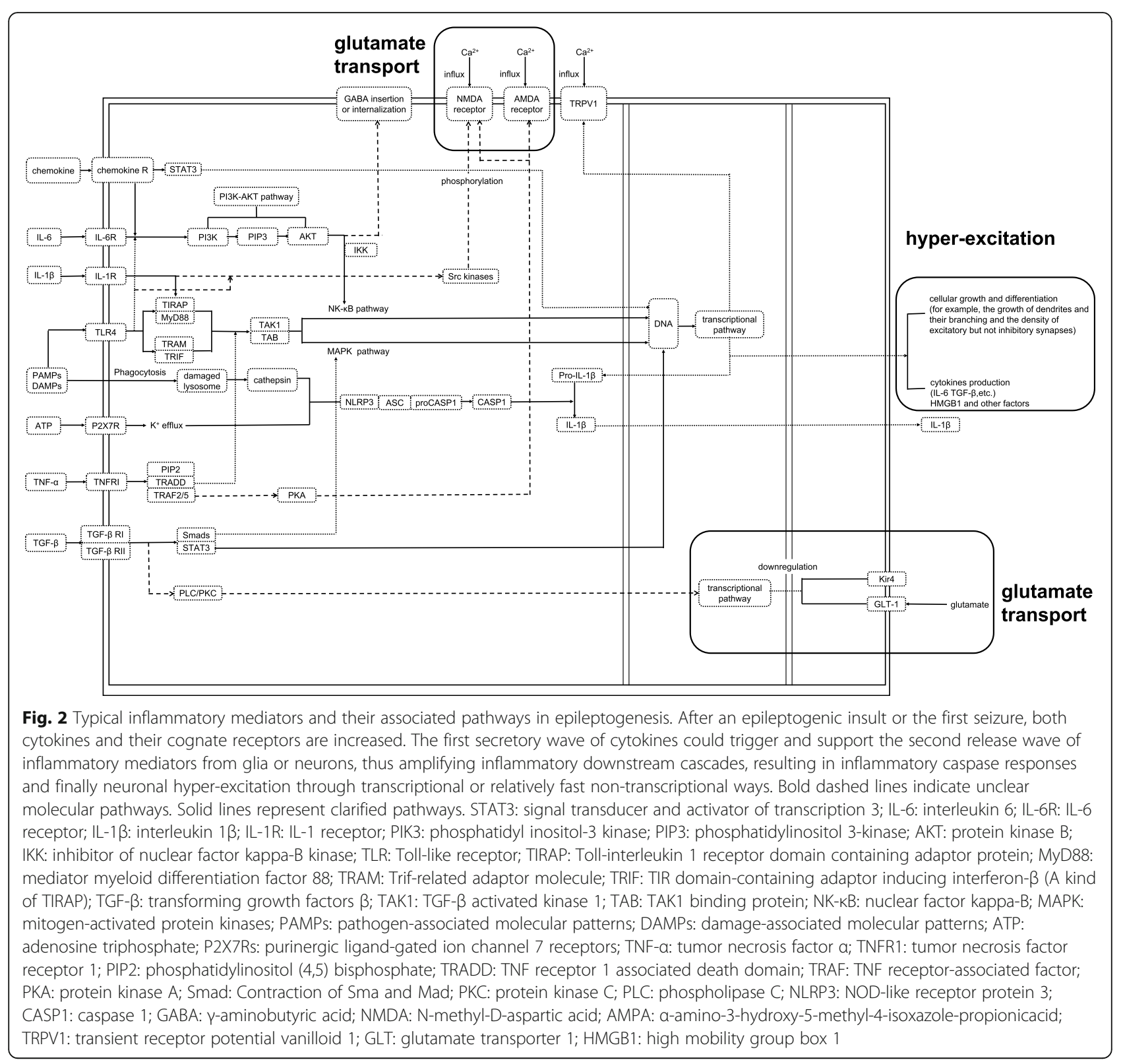

roles of anakinra have been confirmed in a recent study, in which anakinra shows effectively therapeutic effects on a child with febrile infection-related epilepsy syndrome (FIRES) and alleviates the elevated levels of proinflammatory cytokines in the cerebral spinal fluid of this patient [45].

\section{II-6}

IL-6 is a pro-inflammatory factor that is not only a component of the immune system but also a participant in the CNS. IL- 6 and its receptor IL-6R are expressed by astrocytes, microglia, neurons, and endothelial cells [46]. On the one hand, the quantity of IL- 6 can be multiplied via the activation of microglia and astrocytes [47]. On the other hand, it can be increased as a sequel of increases of other cytokines such as IL-1 [48] and TNF- $\alpha$ [46]. Although some studies show that IL-6 has neuroprotective effects [49], recent studies suggest that IL-6 participates in epileptogenesis. IL-6 may have both proconvulsive and anti-convulsive effects, possibly depending on its concentration, duration, and the impact of other inflammatory mediators. Animal experiments using pharmacological approaches demonstrate that IL-6 can change the PI3K/AKT-dependent $\mathrm{GABA}_{\mathrm{A}} \mathrm{R}$ insertion/internalization and then the availability of cytosolmembrane GABA $_{\mathrm{A}} \mathrm{R}$. Afterward, IL- 6 reduces the amplitude of $\mathrm{GABA}_{\mathrm{A}} \mathrm{R}$-mediated inhibitory currents without altering the glutamatergic excitation state [50]. In 
addition, the IL-6 receptor inhibitor tocilizumab terminates SE in 6 of 7 patients suffering from new-onset refractory status epilepticus, although 2 of 7 patients experience adverse side effects [51]. Therefore, more research is warranted to advance understanding of the precise role of IL-6 in epileptogenesis.

\section{TNF- $a$ with dual functions}

TNF- $\alpha$ is mainly expressed by glial cells and BBB endothelial cells [52], and its expression may be potentially induced by interferon- $\gamma$ (IFN- $\gamma$ ) and activated P2X7Rs $[53,54]$. Under such conditions as ischemia trauma, infection, and neuronal excitotoxicity, TNF- $\alpha$ can, on the one hand, influence cell viability, while on the other hand, promoting rapid changes in neuronal excitation. Mice with excessively high levels of TNF- $\alpha$ have high risks of neurological disorders, including epilepsy [55]. The function of TNF- $\alpha$ can be modulated by different target cells (neurons, and glial cells, and endothelial cells of $\mathrm{BBB}$ ) and the ratio of different types of TNF- $\alpha$ receptors [56]. There are two types of TNF- $\alpha$ receptors, receptor R1(TNFR1, p55TNFR) and receptor R2(TNFR2, p75TNFR), which serve opposite functions. Animal experiments indicate that the $\mathrm{p} 75$-receptor knockout mice exhibit increased seizure susceptibility, while the p55receptor knockout mice show reduced seizure incidence [57]. In AMPA( $\alpha$-amino-3-hydroxy-5 -methylisoxazole4-propionic acid)-induced excitotoxic mouse hippocampal slices, high-dose TNF- $\alpha$ has pro-ictogenic effects by binding the p55 receptor, while low-dose TNF- $\alpha$ stimulates the p75 receptor, thereby generating anti-ictogenic effects [58]. The p55 receptors are also persistently increased in NeuN-immunoreactive neurons at 2-48 h after seizure onset, while the expression of p75 receptors in NeuN-positive CA1 and CA3 pyramidal cells continues to decline after a transient up-regulation at $2-6 \mathrm{~h}$ after seizure onset [56]. However, the activation of p75 receptors expressed on $\mathrm{BBB}$ endothelial cells can contribute to the increased $\mathrm{BBB}$ permeability. In the SEinduced vasogenic edema rat model, the TNF- $\alpha / \mathrm{p} 75$ receptor-mediated Thr 485 phosphorylation of p65 $\mathrm{NF} \kappa \mathrm{B}$ subunit is involved in the impairment of endothelial cell function and subsequent BBB disruption [59]. Moreover, TNF- $\alpha$ augments the synaptic availability of $\mathrm{Ca}^{2+}$-permeable AMPA receptors and NMDAR NR1 subunit, thus increasing the excitatory synaptic activity [56]. Furthermore, TNF- $\alpha$ can promote microglial glutamate release in an autocrine manner [60], and trigger astrocytic glutamate exocytosis via the production of prostaglandins (PGs) and the following elevation of intracellular $\mathrm{Ca}^{2+}[61]$. TNF- $\alpha$ can also inhibit the astrocytic glutamate uptake by reducing the expression of glutamate transporters [62]. TNF- $\alpha$ and p55 receptors mediate neuronal loss and demyelination probably by inducing penetration of $\mathrm{T}$ cells or activating resident microglia in intractable pediatric epilepsy [63]. The antiTNF- $\alpha$ therapy has demonstrated potential clinical applications in a recent study. Adalimumab treatment as an anti-TNF- $\alpha$ therapy significantly reduces the seizure frequency in 11 SE patients, from a median of 360 to a median of 32 seizures per quarter [64].

\section{TGF- $\beta$ pathway}

TGF- $\beta$ is a member of the TGF family and is involved in physiological and pathological cellular processes, including cell growth, migration, apoptosis, inflammation, and extracellular matrix expression $[65,66]$. Release of active TGF- $\beta$ is controlled by many factors, such as proteases, ROS, and integrins. The activation of the TGF- $\beta$ signaling pathway itself can also increase the generation of TGF- $\beta$ as a positive feedback. Numerous types of CNS cells can produce TGF- $\beta$, including neurons, endothelial cells, microglia, and astrocytes. The TGF- $\beta$ pathway is initiated by binding to a tetradic complex composed of TGF- $\beta$ receptor II and TGF- $\beta$ receptor I. Both receptors are serine/threonine kinases that can phosphorylate the Smad proteins. The downstream signaling involves interaction with Smad proteins to form specific complexes, which then promote transcriptional activities [67].

After administration of TGF- $\beta$ R1 kinase inhibitor SB431542, and/or the antibody of TGF- $\beta R 2$, SB431542, the number of FITC-albumin-labelled-cells in rat cortical slices is reduced, which suggests that the endocytosis of albumin in the CNS is mediated by the TGF- $\beta$ signaling pathway [68]. Moreover, after BBB breakdown, the uptake of serum albumin by astrocytes can be activated through the TGF- $\beta$ signaling pathway and vice versa [69]. After binding to albumin, the astrocytic TGF$\beta$ receptors can increase neuronal excitability, induce the expression of pro-ictogenic inflammatory mediators, down-regulate gap junction proteins (connexin 30 and 43 ), and influence the astrocytic $\mathrm{K}^{+}$and glutamate buffering. The activated TGF- $\beta$ pathway can down-regulate the Kir channels via phospholipase $\mathrm{C}$ and protein kinase $C-\delta$ in reactive astrocytes [70]. The reduction of $\mathrm{K}^{+}$ current-buffering capability triggers $\mathrm{K}^{+}$accumulation in the synaptic cleft, which might activate NMDAR, and depolarize the post-synaptic membrane and consequently reduce glutamate transport into astrocytes [68]. Besides, TGF- $\beta$ induces the rapid up-regulation and secretion of IL-6 by enhancing astrocytic-specific Smad2/3 phosphorylation and nuclear translocation, thereby inducing the neuronal excitotoxicity and final epileptic seizures [71].

\section{Platelet-activating factor (PAF)}

PAF is a mediator of inflammation that mainly accumulates in the synaptic cleft [72]. PAF functions via its 
receptor to induce intracellular $\mathrm{Ca}^{2+}$ changes and increase early gene expression, thereby triggering downstream responses. PAF participates in the inflammatory processes, stimulates glutamate release, inhibits the activities of GABAergic receptors, mediates the synaptic function by activating the transcriptional signaling pathways of COX-2, and involves in long-term potentiation [72-74], all of which are related to seizure induction.

\section{Chemokines}

Chemokines are another small class of cytokines that can be divided into four subtypes based on structure motif, namely $\mathrm{C}, \mathrm{CX} 3 \mathrm{C}, \mathrm{CC}$, and $\mathrm{CXC}$. Chemokines can be expressed by neurons, glia, endothelial cells, infiltrating leukocytes and monocytes, and can bind G-proteincoupled-receptors. Apart from common effects like mediating leukocyte recruitment and trafficking across the $\mathrm{BBB}$, emerging evidence has shown that chemokines also serve as neuromodulators in the pathogenesis of several neurological diseases, including epilepsy [75]. For example, elevated levels of monocyte chemoattractant protein-1 (MCP-1/CCL2) have been detected in the brains of patients with intractable epilepsy [76]. The peripheral CCL2 can cross the BBB, possibly due to the increased permeability of $\mathrm{BBB}$ and interaction with caveolin-1 [77]. CCL2 can affect the balance between neuronal excitation and inhibition by altering $\mathrm{Ca}^{2+}$ flux [78], reducing GABA-induced currents, or potentiating excitatory post-synaptic currents [79]. CCL2 can also indirectly induce the synthesis of other pro-inflammatory factors such as IL-1 $\beta$, whose roles have been summarized above [80]. C-X3-C motif chemokine ligand 1 (CX3CL1) can induce a use-dependent decrease (rundown) of GABA currents in resected tissues from MTLE patients [81]. Besides, in cultured human or mouse astrocytes, researchers have found that CXCR4 (C-X-C motif chemokine receptor 4) stimulated with $\alpha$-isoform of CXC-chemokine stromal cell-derived factor1 (SDF$1 \alpha$ ) could augment the egress of TNF- $\alpha$ through the extracellular signal regulated kinase (ERK)/MAPK and then the metalloproteinase-dependent pathway [61]. In another study, application of recombinant CXCL1 protein directly to the cultured hippocampal astrocytes triggers astrogliosis and suppresses glutamate transporter-1 (GLT-1) function, further confirming the pathogenic roles of CXCL1 [82]. Furthermore, researchers have found that the expression of CXCR7 is significantly upregulated in the hippocampal dentate gyrus (DG) of KAinduced epilepsy mice, and selectively regulates the NMDAR NR2A subunit-mediated synaptic transmission in hippocampal dentate granule cells by modulating the membrane expression of NR2A [83]. Given the large variety of chemokines, more investigations are needed to discover their pro-ictogenic effects.
In addition to the cytokines noted above, new candidates are emerging with the progress of research. For example, compared to the control group, the serum level of IL-17A is elevated markedly in patients with epilepsy, and is independently correlated with the severity of seizures, suggesting that IL-17A is involved in the pathogenesis of epilepsy [84]. However, all of these findings might just be the tip of the iceberg; more studies are required to reveal the exact mechanisms. Understanding the neurobiology of cytokines will contribute to the advancement of preclinical measures and treatment for epilepsy.

\section{Other inflammatory mediators COX-2}

$\mathrm{COX}$ is a rate-limiting enzyme responsible for the biosynthesis of PGs and thromboxane A2 (TXA2). COX mainly comprises two isoforms, COX-1 and COX-2. COX-1 is widely expressed throughout the body, and in CNS, it is primarily expressed by microglia and perivascular cells, playing essential roles in physiological and pathological conditions. A previous study has found that the expression of COX-1 in microglia is significantly higher than that in either astrocytes or neurons in hippocampal surgical specimens from 33 patients with drug-resistant MTLE [85]. On the contrary, COX-2 is expressed at a relatively low level under normal conditions and can be detected at post-synaptic dendrites and excitatory terminals. However, its expression can be robustly increased under conditions of stroke, traumatic brain injury (TBI), CNS infection, seizure recurrence [86], and after activation of PAF and NMDA [87]. Although some research has shown that COX-1 has significant effects on the neuroinflammatory process of neurodegenerative diseases [88], the association between COX-1 and epilepsy remains unclear. A study has found that SC-560 (a selective COX-1 inhibitor; 5 and $10 \mathrm{mg} /$ $\mathrm{kg}$ ) could delay the progression of seizures in an electrical kindling animal model, which highlights the possible roles of COX-1 in epileptogenesis [89]. Nevertheless, still more evidence is needed to make this conclusion. Unlike COX-1, there seem to be more studies investigating the precise role of COX-2. Some studies have indicated that $\mathrm{PGE}_{2}$, the main PG product of induced COX-2 [90], could increase astrocytic glutamate release, induce neuronal hyper-excitation, and mediate synaptic plasticity $[91,92]$. Research shows that the increased COX-2 expression in CA1 pyramidal cells and dentate granule cells induces the degeneration of GABAergic interneurons after seizures [91]. Furthermore, administration of a selective COX-2 inhibitor NS398 at 5 h after kainite injection blunts neuronal loss in rats [93]. Another experiment shows that selective COX-2 inhibitors significantly reduce post-synaptic 
membrane excitability and back-propagating dendritic action potential-associated $\mathrm{Ca}^{2+}$ influx in hippocampal dentate granule neurons [94]. However, there has been accumulating evidence showing that COX-2 plays a bidirectional role in the pathogenesis of seizures. Some studies show that pre-treatment with selective or nonselective COX-2 inhibitors has a pro-convulsant effect [95-97], while post-treatment with COX-2 inhibitors has a neuroprotective effect [98-100]. The dual impacts may be due to the early neuroprotective and the late neurotoxic roles of COX-2, as well as the drug dose, duration, use of different seizure inducers and many other factors. Researchers have also found that the selective COX-2 inhibitors could not prevent the advancement of epileptogenesis or reduce the frequency of seizure recurrence in animal models of epilepsy [94]. This suggests that COX-2 participates in the progression of epilepsy and has disease-modifying effects, but is not a determining factor for epileptogenesis [7].

\section{The complement system}

The complement system includes a series of cellmembrane proteins and is the major effector of innate immunity and adjuvant of adaptive immunity. The complement system can be stimulated via three different pathways: the classical, alternative, and lectin, and finally form membrane attack complexes (MACs) [101]. In response to slight insults without the destruction of BBB, complement proteins are synthesized locally by astrocytes, microglia, neurons, and oligodendrocytes at relatively low levels. However, in the presence of severe or chronic insults with BBB breakdown, complement proteins are mainly synthesized by infiltrating peripheral immune cells. The activators of the complement system can be infection inducers, DAMPs (HMGB1), apoptotic cells, and necrotic cells [101, 102]. Once activated, the complement system can activate microglia-mediated synaptic pruning [103], induce secretion of proinflammatory cytokines, and affect neuronal excitatory state [101]. It has been found that the classical complement pathway is dramatically activated in patients with epilepsy, based on the observation that the levels of $\mathrm{C} 1 \mathrm{q}$ and $\mathrm{iC} 3 \mathrm{~b}$ (main constitutive protein of classical complement pathway) are significantly increased in surgicallyresected cortical samples from patients with refractory epilepsy [104], suggesting that the C1q-C3 signaling is a potential mediator of epileptogenesis. Furthermore, a study indicates that the expression of $\mathrm{CFH}$ (an inhibitor of the alternative pathway of complement activation) is down-regulated in the hippocampus of a chronic TLE rat model, which suggests the pathogenic effects of the alternative pathway of complement activation [40]. Others have found that $\mathrm{C} 3 \mathrm{a}$ and $\mathrm{C} 5 \mathrm{a}$ increase the expression of cell adhesion molecules (CAMs), including intercellular cell adhesion molecule 1 (ICAM-1), vascular cell adhesion molecule 1 (VCAM-1), P-selectin and E-selectin. Subsequently, they activate brain endothelial cells, increase leukocyte-endothelial interaction, and thereby cause the infiltration of peripheral immune cells into the brain parenchyma [105]. All of these alterations can induce abnormal excitation of neurons.

\section{CAMs}

CAMs are proteins involved in a wide array of physiological processes such as cell differentiation, cell growth inhibition, and apoptosis, especially leukocyte trafficking. In vivo studies have shown that after epileptiform activities, CAMs such as VCAM-1, ICAM-1, and P-selectin are up-regulated in brain endothelial cells, which usually bind to integrins and mucins expressed by circulating leukocytes. Blockade of $\alpha 4$ integrins has a therapeutic effect in the experimental model of pilocarpine-induced epilepsy, in that it inhibits the rolling and arrestment of granulocytes and Th1 lymphocytes in cerebral vessels induced by the activation of leukocytes [106]. The CAMmediated leukocyte-endothelial interactions induce seizures mainly by increasing the vascular leakage, triggering $\mathrm{BBB}$ opening, and activating neuroinflammation.

\section{ROS}

ROS are byproducts of various metabolic reactions, mainly consisting of superoxide anion $\left(\mathrm{O}^{-}\right)$, hydrogen peroxide $\left(\mathrm{H}_{2} \mathrm{O}_{2}\right)$, and the hydroxyl radical $(\mathrm{OH} \bullet)$. ROS are not only well-known cell-damaging agents but also mediators of many physiological signaling pathways, including cell proliferation, differentiation, autophagy as well as immune responses. ROS are important participants in the pathogenesis of epilepsy; they mediate the seizure-induced neuronal damage and the oxidation of ion channels and neurotransmitter transporters, which ultimately amplify neuronal excitability by influencing the plasma membrane potential actions and reduce the network inhibition by suppressing inhibitory interneurons [107, 108]. Moreover, recent research shows that the ROS are involved in epileptogenesis by influencing the inflammatory pathways. After pharmacological antioxidant treatment by injecting $\mathrm{Mn}$ (III) tetrakis $\left(\mathrm{N}, \mathrm{N}^{\prime}\right.$ diethyl imidazolium-2-yl) porphyrin ( $\mathrm{Mn}^{\mathrm{III}}$ TDE-2$\mathrm{ImP}^{5+}$ ) into the pilocarpine-induced epilepsy rat model, researchers have found that the SE-induced proinflammatory cytokine production and microglial activation are attenuated [35]. Upon activation of TLRs, transcription of ROS is induced, which in turn induces the release of HMGB1, a factor that can promote seizures by activating TLR4 and RAGE (as described above) [109]. ROS can also amplify the production of proinflammatory cytokines through the redox-sensitive transcriptional factors such as NK-kB [110] and MAPK 
[111]. In another study, treatment with MnIIITDE2IMp5+ significantly attenuates the phosphorylation of ribosomal protein S6 (a downstream target of the mTOR pathway) in a pilocarpine-induced SE rat model. However, the level of p-ERK (another redox-sensitive transcriptional factor) is not significantly reduced. Therefore, the mTOR pathway may participate in the pathogenesis of oxidative stress in epilepsy [35].

\section{The mTOR pathway}

mTOR is a highly conserved serine/threonine-protein kinase, belonging to the kinase family of PI3K. mTOR functions mainly through two multimeric complexes, mTORC1 and mTORC2. There are numerous upstream modulators of mTOR, including PI3K, AKT (PKB), and epidermal growth factor receptor (EGFR) [112]. As noted above, some inflammatory mediators (such as IL-1 $\beta$ and ROS) can function through the mTOR pathway in epileptogenesis, and IL-1 $\beta$ has been found to participate in epilepsy by activating mTOR upstream regulators $[35,42]$. The mTOR pathway is critical for biological processes of the CNS, including cortical development, axonal and dendritic morphology, immune responses, neurotransmitter expression, ion channel expression, synaptic plasticity, cognition, and behavior [113, 114]. Disturbance of the mTOR pathway and the subsequent abnormal state of the above biological processes can contribute to the development of epilepsy. Numerous studies have shown the pathogenic roles of the mTOR pathway in epileptogenesis. However, how the mTOR pathway participates in immune-associated pathogenic mechanisms of epilepsy has only recently begun to be investigated. Rapamycin treatment significantly reduces $\mathrm{BBB}$ leakage in the piriform cortex and amygdala of a KA-induced rat SE model [115], suggesting that the mTOR pathway is pro-ictogenic by breaking the integrity of $\mathrm{BBB}$. Besides, the deletion of mTOR in reactive astrocytes attenuates seizure frequency and astrogliosis in a KA-induced TLE rat model [116]. Treatment with everolimus, another mTOR inhibitor, retards the microglial activation in the hippocampus of a KA-induced epilepsy mouse model [117]. However, neither everolimus nor rapamycin reduces the expression of IL- $1 \beta$, while rapamycin even increases the expression of NLRP3 [117]. In the intracranial electrode-stimulated SE rat model, there is no difference in the expression of IL-1 $\beta$, IL-6, TGF- $\beta$, and HMGB1 between the mTOR inhibitortreated (rapamycin or curcumin) group and the control group [118]. Understanding the relationship between the mTOR pathway and inflammatory mediators in epileptogenesis still requires more investigations.

\section{Classic pro-inflammatory cells in epilepsy} Microglia: different roles at different disease stages Microglia are the resident macrophages in the brain, accounting for approximately $10 \%$ of cells in the brain parenchyma. Microglia have impacts on an array of biological processes in the CNS, including synaptic pruning, maturation and plasticity, phagocytosis, and neuroinflammation $[119,120]$. The microglial cells have two activation states, the classical M1 phenotype and the alternative M2 phenotype. M1 microglia express proinflammatory mediators IL-1 $\beta$ and TNF $\alpha$, while M2 microglia express anti-inflammatory mediators Arg1, IL14, and IL-10. It has been found that M1 and M2 markers are expressed simultaneously in microglia cells, suggesting complex roles of microglia in the CNS [120]. The exact roles of microglia could be either proictogenic or anti-ictogenic in epileptogenesis, depending on the duration and strength of the stressor, the ratio of M1 and M2 microglial phenotypes, and the proportion of diverse microglial receptors.

In the presence of acute epileptic insults, microglia may play a beneficial role mainly through P2Y12Rs, which mediate acute microglial responses to ATP in the brain. After intracerebroventricular or intraperitoneal injection of KA, the seizures are exacerbated in P2Y12Rdeleted rats [121]. The microglial P2Y12Rs are also essential for microglia-neuron interactions in mice with KA-induced epilepsy [122]. Another study shows that microglia can use TLR9 to sense self-DNA released by dying neurons, and then secrete TNF- $\alpha$, thus inhibiting the proliferation of neural stem cells (including granules cells in epileptic zones), which would attenuate the aberrant neurogenesis [123, 124].

Microglia can trigger seizures by releasing or responding to pro-inflammatory mediators. As we summarized above, the release of pro-inflammatory mediators by microglia can play pro-convulsive roles by affecting the buffering of neurotransmitters and ions, contributing to the permeability of $\mathrm{BBB}$, and aggravating the inflammatory caspases. As for the response to pro-inflammatory mediators, for example, microglial cells can be proictogenic through CXCR4 signaling [125]. CXCR4 signaling can induce the release of microglial TNF- $\alpha$ as well as astrocytic glutamate and finally result in neuronal hyper-excitation.

It has been indicated that acute activation of microglia will play a neuroprotective role [126], while chronicallyactivated microglia might be neurotoxic. In the end, when and how microglia play a pro-convulsive role is still a topic that needs further investigations.

\section{Astrocytic inflammatory responses in epilepsy}

Astrocytes have numerous physiological functions, including but not limited to, synaptic formation, providing 
nutrition and antioxidants to neurons, orchestrating extracellular balance of ions and neurotransmitters, and neuroinflammation [127]. Astrocytes are not only important sources of pro-inflammatory mediators but also the main targets of them. Cytokines released by astrocytes can either act on themselves in an autocrine way or on nearby cells in a paracrine manner. Accumulating evidence has demonstrated that the astrocyte-mediated immune responses induced by pathogens or noninfectious insults can promote epileptogenesis.

The activation of astrocytes by inflammatory mediators could amplify the immune responses in CNS. The initiators of neuroinflammation, such as IL- $1 \beta$ and HMGB1, could act on their astrocytic cognate receptors, thereby inducing Src kinase-mediated phosphorylation of the GluN2B subunit of the NMDAR, and augmenting astrocytic $\mathrm{Ca}^{2+}$ signaling [128]. Then the nitric oxide synthases activated by NMDAR-mediated $\mathrm{Ca}^{2+}$ influx can convert L-arginine into nitric oxide (NO) under epileptogenic circumstances. The NO further induces oxidative stress, accompanied by mitochondrial loss, consequently triggering a vicious circle of neuronal damage $[129,130]$. In addition to NO, the enlarged astrocytic $\mathrm{Ca}^{2+}$ signaling is also involved in the release of ATP, PGs, cytokines, neuropeptides, and glutamate [131].

Astrocytes can also play a neuroprotective role. They can induce anti-inflammatory responses by expressing IL-1RA. However, in brain specimens of chronic intractable epileptic patients due to focal cortical dysplasia (FCD), the expression level of IL-1RA is significantly lower than that of IL-1 $\beta$ in astrocytes [132].

The astrocytic end feet wrap around the endothelial cells, forming an essential structure of $\mathrm{BBB}$, and astrocytes influence the integrity of BBB by releasing a plethora of molecules. Cytokines and glutamate released by abnormally-activated astrocytes will cause or exacerbate the permeability of $\mathrm{BBB}$, possibly by increasing the expression levels of matrix metalloproteinases (MMP-2 and MMP-9) in BBB $[133,134]$. In turn, further leakage of albumin caused by BBB dysfunction activates and mediates the TGF- $\beta$ pathway in astrocytes, resulting in the down-regulation of transcription of Kir4, aquaporin 4 (AQP4) channel and GLT-1 [135, 136]. Kir4.1 channels mediate the astrocytic $\mathrm{K}^{+}$buffering. The decreased expression of Kir4 increases the level of extracellular $\mathrm{K}^{+}$ and facilitates the NMDA-induced neuronal excitotoxicity $[136,137]$. GLT-1, also known as EAA2, is one of the effective sodium ions $\left(\mathrm{Na}^{+}\right)$-dependent glutamate transporters in the astrocytic glutamate reuptake system and controls the concentration of extracellular glutamate [138]. The GLT-1 down-regulation in the context of BBB disruption is accompanied by electrophysical evidence of reduced glutamate buffering [135]. And in mouse models with cortical dysplasia, researchers have found that selective inhibitors of GLT-1 lower the threshold of seizures, thus enhancing the neuronal excitation [139]. Besides, pro-inflammatory mediators can also mediate the astrocytic glutamate release, inhibit glial glutamate reuptake, and affect the astrocyte-neuron interactions. Some researchers have found that LPS injection in young mice promotes the generation of neuronal over-excitation, which is mediated via the astrocytic TLR4-MyD88-ERK1/2 pathway. Apart from the wellknown pro-inflammatory effects, the TLR4-MyD88ERK1/2 pathway can also promote dendritic growth and branching, and increase the density of excitatory rather than inhibitory synapses [140]. In addition, astrocytes can also sense the abnormal level of ATP and then initiate the purinergic pathways, affecting the activation of microglia and the release of neurotransmitters.

\section{Adaptive immune cells: infiltrating players}

Emerging experimental evidence has demonstrated that some seizures develop after the infiltration of adaptive immune cells in the CNS, which is always accompanied by the breakdown of BBB. The infiltration of immune cells often occurs in patients with autoimmune epilepsy, and such immune infiltration is usually dominant and abundant. Some other researchers have found infiltration of lymphocytes in TLE models with hippocampal sclerosis of unknown etiology; in fact, considerable amounts of infiltrating $\mathrm{T}$ cells have been found in some specific types of TLE, such as the post-encephalitic TLE. Infiltration of lymphocytes in the CNS has also been found in a specific subgroup of FCD, although the invasion of lymphocytes is relatively low [141]. Most of the infiltrating $\mathrm{T}$ cells are cytotoxic to normal neurons, induce hyper-excitation of the neurons, and modify the seizure threshold through releasing TNF- $\alpha$, IL-17, and granulocyte-macrophage colony-stimulating factor. The number of infiltrating $\mathrm{T}$ cells is also closely correlated with the severity of seizures [63, 142]. Both infiltrating $\mathrm{CD}^{+}$and $\mathrm{CD}^{+} \mathrm{T}$ cells are observed to express high levels of integrins (very late antigen-4 and lymphocyte function-associated antigen-1) in the brains of 33 drugresistant epileptic patients with Rasmussen's encephalitis, or encephalomalacia (EM), or MTLE, or FCD. These integrins are essential for $\mathrm{T}$ cell migration across $\mathrm{BBB}$. In drug-resistant epileptic patients with $\mathrm{EM}$ or FCD, neurons and mature oligodendrocytes are found to express MHC molecules in resected brain tissues, making them possible targets for $\mathrm{T}$ cells, thereby triggering $\mathrm{ab}$ normal losses of myelin sheaths and neurons [63].

On the one hand, infiltrating $\mathrm{T}$ cells can influence the survival of neurons and glial cells, thereby disrupting nerve fibers and synapses. On the other hand, $\mathrm{T}$ cells can secrete certain pro-inflammatory molecules to induce hyper-excitation of neurons. 


\section{Typical receptors involved in epileptogenesis P2Rs}

The P2Rs are divided into ionotropic P2XRs and metabotropic P2YRs. The P2XRs are trimers consisting of subunits from seven subtypes, namely P2X1R-P2X7R, and they almost exclusively recognize ATP. Upon ATP binding, the P2XRs can modulate the plasma membrane permeability to $\mathrm{Na}^{+}, \mathrm{K}^{+}$, and $\mathrm{Ca}^{2+}$ in a non-selective manner, participate in neuronal and glial survival, differentiation, proliferation, and the activation of microglia as well as astrocytes [29]. Information on the immunological roles of P2XRs except for P2X7Rs in epileptogenesis is rather limited. A recent study shows that the administration of NF110 (a potent antagonist of P2X3Rs) significantly increases the latency of kindling and decreases the levels of IL- $1 \beta$ and TNF- $\alpha$ in pentylenetetrazole (PTZ)-treated rats, which suggests that P2X3Rs play a pro-ictogenic role in epilepsy [143].

The P2YRs function through binding to adenine and uridine nucleotides and they are involved in numerous biological processes, including neuronal and glial survival and growth, inflammation, regulation of neurotransmitters and voltage-gated ion channels, as well as alterations in the expression or function of other membrane receptors [144]. All P2YRs subtypes share the seven-transmembrane-domain and can be divided into two subgroups based on the G-protein coupling and the physiological function, the P2Y1Rs, P2Y2Rs, P2Y4Rs, P2Y6Rs, and P2Y11Rs subgroup and the P2Y12Rs, P2Y13Rs, and P2Y14Rs subgroup. Receptors of the first subtype are coupled to Gq/G11 to activate the phospholipase $\mathrm{C} /$ inositol triphosphate endoplasmic reticulum $\mathrm{Ca}^{2+}$ release pathway, while receptors of the second subtype are coupled to Gi/o to inhibit the adenylyl cyclase and modulate ion channels [29]. P2Y6Rs and P2Y12Rs can activate microglia by interacting with UDP and ATP, respectively [143]. After the occurrence of acute epileptic insults, microglia can play a neuroprotective role mainly through P2Y12Rs [121, 122], and it has been found that the microglial P2Y12Rs are necessary for the microglia-neuron interactions in KA-treated epilepsy mice [122]. However, the roles of certain P2YRs can be divergent depending on specific downstream pathways. For example, P2Y1Rs are expressed on astrocytes and bind to ADP under oxidative stress. The ADP-P2Y1Rs axis can promote the release of IL-6, which has both anti-inflammatory and pro-inflammatory functions. The activated P2Y1Rs may have a bidirectional effect on the severity of seizures depending on when the manipulation of P2Y1Rs is performed. Studies have shown that activating P2Y1Rs before the induction of SE can reduce seizures, while P2Y1Rs activated after SE is triggered may be pro-convulsive, possibly through the activation of microglia [145].
The P2R family also participates in the epileptogenesis by affecting the release of neurotransmitters. For example, the release of astrocytic neurotransmitter can be enhanced by P2X1Rs, P2X3Rs, P2X2/3Rs, and P2X7Rs, and inhibited by P2Y1Rs, P2Y2Rs, and P2Y4Rs [144]. Disturbed balance of purinergic receptors with opposite functions may be a vital mechanism for seizures.

Overall, once activated by DAMPs, the purinergic receptors, on the one hand, could be directly involved in the release of pro-inflammatory cytokines, and on the other hand, could influence the activity of glial cells and the release of neurotransmitters.

\section{TLRs}

TLRs are conserved type-I transmembrane proteins and the most studied PRRs, consisting of ten members. TLRs are expressed in both glial cells and neurons and can detect a wide range of pathogens and DAMPs [39]. TLRs can be activated in response to infection or other sterile insults (such as brain trauma and autoimmunity) to trigger the downstream NF-kB, MAPK, and/or IRF signaling pathways, mediate the production of cytokines, enzymes, and other inflammatory mediators, and thereby exacerbate immune responses [146], reduce the seizure threshold and induce epileptogenesis [147]. Over-expression of TLR4 and its endogenous ligand HMGB1 has been found in epileptic models, and its effect has been demonstrated (see the HMGB1 part above). Besides, TLR3 activation leads to the production of type-I IFNs, which are essential neuro-modulators to enhance the excitability of neurons, and ultimately increase the seizure susceptibility of rats. TLR3 deficiency reduces the recurrence of spontaneous seizures by reducing microgliosis and the expression of pro-inflammatory cytokines [148]. A recent study has found activation of the TLR7 pathway in cortical tissues obtained from surgery of tuberous sclerosis (TSC) children with drug-resistant epilepsy, suggesting that TLR7 contributes to the neuroinflammatory cascade in epilepsy in TSC [149]. Moreover, other studies have found that TLR9 signaling in microglia could sense self-DNA as a DAMP and then attenuate seizure-induced aberrant neurogenesis in the adult hippocampus by inducing TNF- $\alpha$ expression [123]. The TLR-mediated immune responses can exert either beneficial or detrimental effects on seizures and their recurrence, possibly depending on the strength and duration of the activating signals and the type of TLRs [146], which needs further investigations.

\section{BBB dysfunction and leakage}

$\mathrm{BBB}$ is a functional structure responsible for maintaining the homeostasis of the internal CNS environment. BBB dysfunction can be triggered by hypoxia, craniocerebral trauma, inflammatory activation, and some other 
Table 1 Neurological and non-neurological diseases associated with epilepsy and the related inflammatory mediators

\begin{tabular}{|c|c|c|c|}
\hline \multicolumn{2}{|l|}{ Disease } & \multirow{2}{*}{$\begin{array}{l}\text { Inflammatory mediators contributing to epilepsy development } \\
\text { HMGB1, IL-1 } \beta, \text { IL-6, TGF- } \beta, C C L 2 \text {, complement, ROS, albumin, } \\
\text { microglia, BBB, T cells }\end{array}$} & \multirow{2}{*}{$\frac{\text { Reference }}{[158-164]}$} \\
\hline $\begin{array}{l}\text { Neurological } \\
\text { Diseases }\end{array}$ & Brain trauma & & \\
\hline & Stroke & IL-1 $\beta$, TNF-a, IL-6, ICAM, VCAM, CX3CL1, MMP-9, BBB & $\begin{array}{l}{[163,} \\
165-167]\end{array}$ \\
\hline & Subarachnoid hemorrhage & DAMPs, IL-1 $\beta, I L-6$, TNF- $a$ & {$[168,169]$} \\
\hline & Brain tumors & IL-1 $\beta$, TNF- $a$, TGF- $\beta$, complement, TLRs, COX, PGs, BBB & {$[163,170]$} \\
\hline & Alzheimer's disease & IL-6, TNF-a, CXCL8, CCL5, MCP-1(CCL2), ROS, complement & [163] \\
\hline & Multiple sclerosis & ROS, T cells, B cells, and macrophages & [163] \\
\hline \multirow[t]{9}{*}{$\begin{array}{l}\text { Non- } \\
\text { neurological } \\
\text { Diseases }\end{array}$} & $\begin{array}{l}\text { Paraneoplastic neurological syndromes } \\
\text { (produce antibodies against neuronal intracellular } \\
\text { and cell-surface antigens and glial antigens) }\end{array}$ & $\begin{array}{l}\text { Antibodies for LGI 1, CASPR2, NR1, GluR1/GluR2, GABA }, \mathrm{Hu} / \\
\text { ANNA-1, Ma2/Ta, GAD65, CV2/CRMP5, and GFAP; T cells; B cells }\end{array}$ & {$[171,172]$} \\
\hline & $\begin{array}{l}\text { Systemic lupus } \\
\text { erythematous }\end{array}$ & 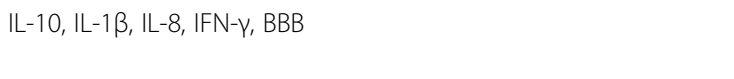 & {$[173,174]$} \\
\hline & $\begin{array}{l}\text { Rheumatoid } \\
\text { arthritis }\end{array}$ & TNF-a, IL-1, IL-6 & [163] \\
\hline & Anti-phospholipid syndrome & Antibodies against membrane anionic phospholipids & [163] \\
\hline & Sjogren's & $\mathrm{CD}^{+} \mathrm{T}$ cells, B cells & [163] \\
\hline & Type I diabetes & $\begin{array}{l}\text { T cells (Encephalitis with antibodies against GAD65), BBB, TNF-a, } \\
\text { IL-12, glutamic acid decarboxylase antibodies }\end{array}$ & $\begin{array}{l}{[172,175,} \\
176]\end{array}$ \\
\hline & Celiac disease & $\begin{array}{l}\text { IL-1 } \beta, \text { IL-6, INF- } \gamma \text {, TNF-a, BBB, T cells, anti-endomysial antibodies, } \\
\text { anti-tissue transglutaminase antibodies, anti-gliadin antibodies }\end{array}$ & {$[163,176]$} \\
\hline & Ulcerative Colitis & IL-5, IL-13, IL-15, Th2 cells & [163] \\
\hline & Hashimoto's thyroiditis & Anti-thyroid antibodies & {$[163,176]$} \\
\hline
\end{tabular}

neurological disorders such as epilepsy, and then the expression of vascular endothelial growth factor (VEGF), IL- $1 \beta$, and immunity-related enzyme COX-2 is promptly increased [150, 151]. It has been shown that the expression of VEGF in neurons and astrocytes and its receptors in endothelial cells is augmented after seizures, which may induce angiogenesis and thereby promote the permeability of BBB [151]. Recent studies have shown that elevated levels of COX-2 play an early neuroprotective and late neurodegenerative role in pyramidal cells, thus exacerbating the BBB leakage [152]. The BBB opening would, in turn, increase the expression of COX-2 [153]. Increased expression of ICAM-1 and VCAM-1 can also prominently induce the $\mathrm{BBB}$ leakage in mice with pilocarpine-induced epilepsy [106, 154]. Although the $\mathrm{BBB}$ dysfunction is generally recognized as a result of epilepsy, recent studies have suggested that the $\mathrm{BBB}$ lesion is an important etiology of epileptogenesis [68, 155]. The abnormal entry of blood components across $\mathrm{BBB}$, including $\mathrm{K}^{+}$, glutamate, and serum albumin, may be an effective cause of epilepsy. It has been shown that the astrocytic uptake of extravasated serum albumin contributes to the neuronal hyper-excitation via the TGF- $\beta$ pathway, which then down-regulates Kir4.1, AQP4, as well as the glutamate transporters GLT1 and GLAST [135, 136, 156]. Apart from astrocytes, the albumin up-take also occurs in neurons and microglia. The neuronal endocytosis of albumin is selective, mainly involving interneurons and pyramidal neurons, and may be indirectly associated with neuronal degeneration and death in TLE patients and epileptic animal models [157]. However, the albumin per se might not be a direct trigger of neuronal degeneration, as direct injection of albumin into the rat brain parenchyma does not induce neuronal degeneration in the rat brain [156].

Since the BBB serves as both a barrier and a communication intermediary for CNS and peripheral immunity, peripheral inflammation might have pathogenic effects on epileptogenesis by interactions of leukocytes with $\mathrm{BBB}$, which will subsequently promote the release of some diffuse pro-convulsant mediators such as $\mathrm{NO}$ and PGs.

\section{Conclusion}

The inflammatory mediators involved in epileptogenesis include increased inflammatory molecules, activated microglia and astrocytes, damaged $\mathrm{BBB}$, and the subsequent infiltrating peripheral immune participants. In addition to epilepsy, CNS abnormalities (such as fever, hypoxia, hypoglycemia, brain tumor, lack of sleep, substance abuse, or TBI) or systematic autoimmune diseases can also induce the onset of seizures. The neurological 


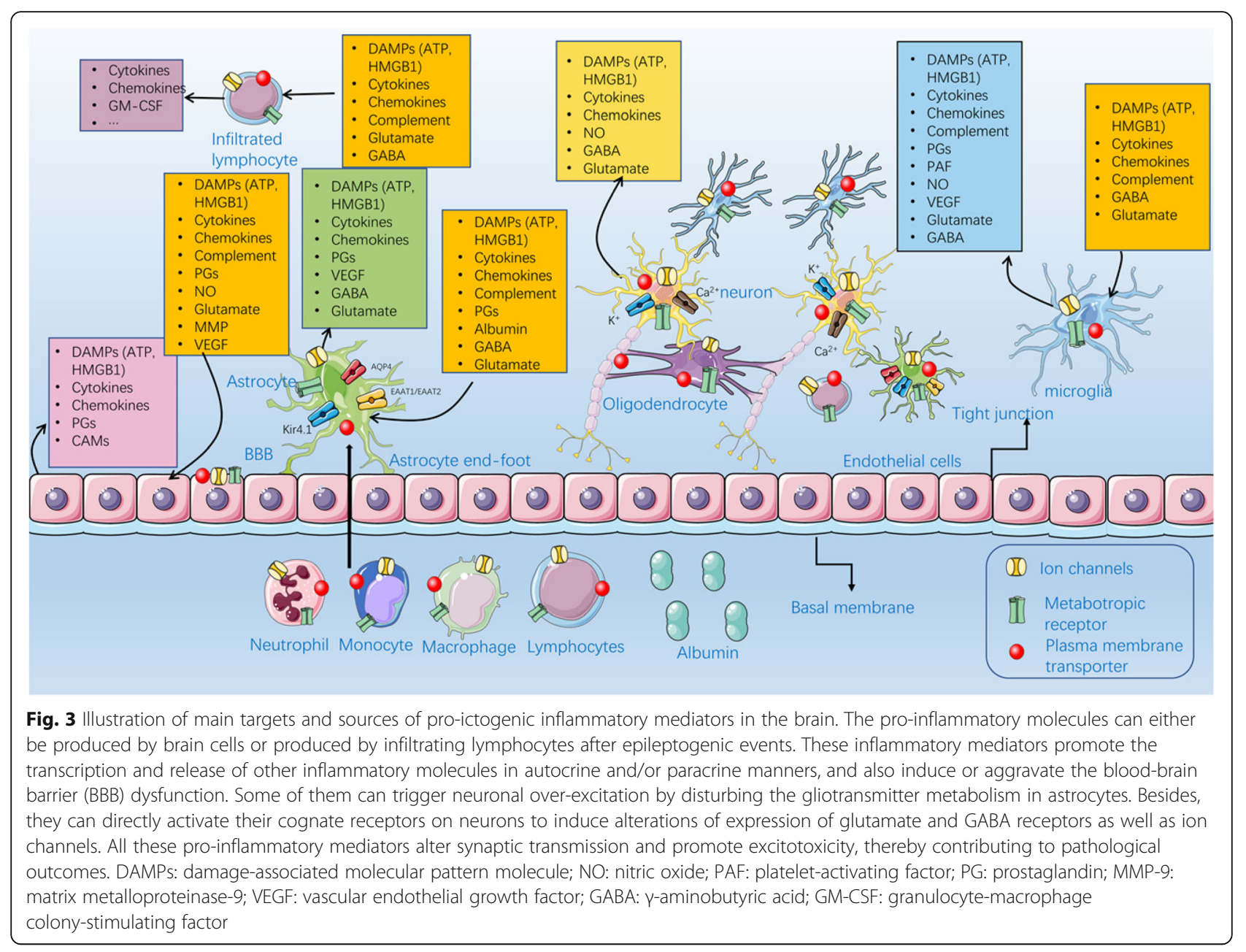

and non-neurological diseases associated with epilepsy, as well as their related inflammatory mediators are summarized in Table 1. Under most circumstances, the development of epilepsy is associated with inflammation in the absence of infection or autoimmune factors. Once activated, neurons and immune cells will release DAMPs, ROS, and pro-inflammatory cytokines, of which the HMGB1/TLR4 and IL-1ß/IL-1R1 signaling

Table 2 Potential anti-inflammatory effects of anti-epileptic drugs

\begin{tabular}{|c|c|c|}
\hline Drug & Inflammatory effect & Reference \\
\hline Valproate & $\begin{array}{l}\text { Inhibit NF-KB and then decrease levels of } \\
\text { TNF-a and IL-16 of monocytes and glia. }\end{array}$ & {$[177]$} \\
\hline Carbamazepine & Increase the cytotoxic activity of NK cells. & {$[177]$} \\
\hline Phenytoin & $\begin{array}{l}\text { Decrease the number of suppressor } \mathrm{T} \text { cells, } \\
\text { and reversibly decrease IgA. }\end{array}$ & {$[177]$} \\
\hline Vigabatrin & Increase the cytotoxic activity of NK cells. & {$[177]$} \\
\hline Levetiracetam & $\begin{array}{l}\text { Reduce reactive gliosis and expression of } \\
\text { IL-1 } \beta \text {. }\end{array}$ & [177] \\
\hline Diazepam & $\begin{array}{l}\text { Inhibit human T cell function and decrease } \\
\text { IFN- } \gamma \text { production. }\end{array}$ & [177] \\
\hline
\end{tabular}

can initiate neuroinflammation. The initial increase of these mediators could stimulate microglia and astrocytes by binding to their corresponding receptors. Then the activated microglia and astrocytes will increase the expression of inflammatory mediators and their cognate receptors. The sustained and extensive immune responses finally lead to the breakdown of $\mathrm{BBB}$ and the consequent permeation of peripheral immune cells and molecules. The pro-inflammatory molecules, on the one hand, keep aggravating the inflammatory cascade reactions, while on the other hand, triggering neuronal hyper-excitation by influencing the release and metabolism of neurotransmitters and affecting ions channels. Furthermore, some pro-inflammatory mediators can bridge peripheral inflammation and neuroinflammation. For example, the astrocytic TGF- $\beta$ receptor can bind to the albumin penetrating across $\mathrm{BBB}$ and activate astrocytes [70]. CAMs can mediate the interaction between leukocytes and endothelial cells in BBB [106]. Glial cells act as both sources and targets of neuroinflammatory molecules in epilepsy. In addition, astrocytes serve as the basic 
Table 3 Anti-epileptic effects of anti-inflammatory treatments in animal models or patients

\begin{tabular}{|c|c|c|c|}
\hline Drug & Experimental model or clinical patients & Anti-epileptic effects & Reference \\
\hline \multicolumn{4}{|l|}{ IL-1 $\beta / I L-1 R$ signaling } \\
\hline \multirow{3}{*}{$\begin{array}{l}\text { VX-765 (A selective } \\
\text { inhibitor of caspase-1/ } \\
\text { ICE) }\end{array}$} & $\begin{array}{l}\text { KA-induced mice that are refractory to some } \\
\text { common anti-convulsant drugs. }\end{array}$ & $\begin{array}{l}\text { VX-765 shows anti- } \\
\text { convulsant activities. }\end{array}$ & {$[178]$} \\
\hline & Electrical rapid kindling in rats & No kindling development after VX-765 treatment. & {$[179]$} \\
\hline & $\begin{array}{l}\text { Drug-resistant focal- } \\
\text { onset epilepsy (adult patients) }\end{array}$ & $\begin{array}{l}\text { The mean percent reduction in seizure rates is } 15.6 \% \text { in the } \\
\text { VX-765 group and } 7.0 \% \text { in the control group. }\end{array}$ & [180] \\
\hline \multirow[t]{2}{*}{$\begin{array}{l}\text { Anakinra (An IL-1R } \\
\text { antagonist) }\end{array}$} & $\begin{array}{l}\text { Acute phase of febrile infection-related epi- } \\
\text { lepsy syndrome (children) }\end{array}$ & Reduce the total number of seizures. & [45] \\
\hline & $\begin{array}{l}\text { Drug-resistant epilepsy (children and } \\
\text { adolescents) }\end{array}$ & Attenuate clinical seizure activity. & [181] \\
\hline \multicolumn{4}{|l|}{ HMGB1/TLR4 signaling } \\
\hline \multirow[t]{3}{*}{$\begin{array}{l}\text { HMGB1 monoclonal } \\
\text { antibody }\end{array}$} & $\begin{array}{l}\text { Maximal electroshock seizure-induced acute } \\
\text { epilepsy in mice }\end{array}$ & Attenuate MES-induced acute seizures. & [182] \\
\hline & PTZ-induced acute epilepsy in mice & Attenuate PTZ-induced acute seizures. & [182] \\
\hline & KA-induced chronic epilepsy in mice & Alleviate the severity of KA-induced chronic epilepsy. & [182] \\
\hline \multicolumn{4}{|l|}{ COX signaling } \\
\hline \multirow{2}{*}{$\begin{array}{l}\text { Nimesulide (A COX-2 se- } \\
\text { lective inhibitor) }\end{array}$} & Electrical rapid kindling in mice & Attenuate the kindling development. & [183] \\
\hline & KA-induced seizures in mice & Pre- or post-treatment aggravates KA-induced seizures. & [96] \\
\hline \multirow[t]{2}{*}{ Aspirin (A COX inhibitor) } & Focal onset epilepsy (adults) & Higher dose correlates with fewer seizures. & [184] \\
\hline & $\begin{array}{l}\text { Sturge-Weber syndrome } \\
\text { (children and adolescents) }\end{array}$ & $\begin{array}{l}\text { In a group of } 58 \text { subjects, } 91 \% \text { of them on aspirin have } \\
\text { good final seizure scores. }\end{array}$ & [185] \\
\hline \multicolumn{4}{|l|}{ TNF signaling } \\
\hline $\begin{array}{l}\text { Adalimumab (An anti- } \\
\text { TNF monoclonal } \\
\text { antibody) }\end{array}$ & $\begin{array}{l}\text { Rasmussen } \\
\text { encephalitis (adults) }\end{array}$ & Decrease seizure frequency in 5 of 11 patients. & [64] \\
\hline \multicolumn{4}{|l|}{ IL-6 signaling } \\
\hline $\begin{array}{l}\text { Tocilizumab (An IL-6 re- } \\
\text { ceptor inhibitor) }\end{array}$ & $\begin{array}{l}\text { New-onset refractory SE } \\
\text { (adults) }\end{array}$ & $\begin{array}{l}\text { SE is terminated in } 6 \text { of } 7 \text { patients; } 2 \text { patients have severe } \\
\text { adverse effects. }\end{array}$ & [51] \\
\hline \multicolumn{4}{|l|}{ Complement } \\
\hline $\begin{array}{l}\text { PMX53 (A C5ar1 } \\
\text { antagonist) }\end{array}$ & $\begin{array}{l}6 \mathrm{~Hz} \text { and corneal kindling epilepsy mouse } \\
\text { models }\end{array}$ & Decrease seizure severity and improve seizure threshold. & [186] \\
\hline \multicolumn{4}{|l|}{ Microglia } \\
\hline $\begin{array}{l}\text { Minocycline (A microglial } \\
\text { activation inhibitor) }\end{array}$ & Drug-resistant focal epilepsy (adults) & Reduce seizure frequency. & [187] \\
\hline
\end{tabular}

structure of $\mathrm{BBB}$, the energy provider, and the neurotransmitter repository. Microglia have essential effects on synaptic pruning, maturation, plasticity, and phagocytosis. The main target and source of pro-ictogenic inflammatory mediators are shown in Fig. 3. Besides, certain inflammatory molecules and cells can have dual roles in the pathogenesis of epilepsy. The underlying mechanisms may be associated with the different triggers of seizures, their intensity, and duration. The excitotoxicity of neurons will, in turn, amplify the immune response. Inflammation seems to be both the cause and the consequence of epilepsy, which means that breaking this vicious cycle may be a candidate strategy for the treatment of epilepsy.
Furthermore, experimental results have demonstrated that some of the current anti-epileptic drugs (AEDs) play specific anti-inflammatory roles in epileptogenesis, and some typical anti-inflammatory drugs also have anticonvulsive effects in animal models and even in clinical epileptic patients (Tables 2 and 3). However, the current knowledge about inflammation and epileptogenesis is not systematic. How do the inflammatory mediators function differentially in acute and chronic phases of epilepsy? As to inflammatory mediators that have bidirectional effects, when and where are they proconvulsive? Should different immunotherapies be used with respect to different triggers? These questions, together with the association between adaptive immunity and epilepsy, need to be investigated in the future. 


\section{Acknowledgments}

This review was supported by the National Natural Science Foundation of China (81471326).

\section{Authors' contributions}

Fanwei Meng wrote, reviewed, and approved the manuscript; Lifen Yao conceived the topic and reviewed and approved the manuscript.

\section{Funding}

This review was supported by the National Natural Science Foundation of China (81471326).

\section{Availability of data and materials}

Not applicable.

\section{Ethics approval and consent to participate}

Not applicable.

\section{Consent for publication}

Not applicable.

\section{Competing interests}

The authors declare that they have no competing interests.

\section{Received: 3 March 2020 Accepted: 13 August 2020}

\section{Published online: 27 September 2020}

\section{References}

1. Fisher RS, Acevedo C, Arzimanoglou A, Bogacz A, Cross JH, Elger CE, et al. ILAE official report: a practical clinical definition of epilepsy. Epilepsia. 2014 55(4):475-82.

2. Singh A, Trevick S. The epidemiology of global epilepsy. Neurol Clin. 2016; 34(4):837-47.

3. Laxer KD, Trinka E, Hirsch LJ, Cendes F, Langfitt J, Delanty N, et al. The consequences of refractory epilepsy and its treatment. Epilepsy Behav. 2014; 37:59-70.

4. Scheffer IE, Berkovic S, Capovilla G, Connolly MB, French J, Guilhoto L, et al. ILAE classification of the epilepsies: position paper of the ILAE commission for classification and terminology. Epilepsia. 2017;58(4):512-21.

5. Siracusa R, Fusco R, Cuzzocrea S. Astrocytes: role and functions in brain pathologies. Front Pharmacol. 2019;10:1114

6. Eyo UB, Wu LJ. Microglia: lifelong patrolling immune cells of the brain. Prog Neurobiol. 2019:179:101614.

7. Shimada T, Takemiya T, Sugiura H, Yamagata K. Role of inflammatory mediators in the pathogenesis of epilepsy. Mediators Inflamm. 2014;2014: 901902

8. Boison D, Steinhäuser C. Epilepsy and astrocyte energy metabolism. Glia. 2018;66(6):1235-43.

9. De Lorenzo G, Ferrari S, Cervone F, Okun E. Extracellular DAMPs in plants and mammals: immunity, tissue damage and repair. Trends Immunol. 2018; 39(11):937-50.

10. Matin N, Tabatabaie $O$, Falsaperla R, Lubrano R, Pavone P, Mahmood F, et al. Epilepsy and innate immune system: a possible immunogenic predisposition and related therapeutic implications. Hum Vaccin Immunother. 2015;11(8):2021-9.

11. Vezzani A, Viviani B. Neuromodulatory properties of inflammatory cytokines and their impact on neuronal excitability. Neuropharmacology. 2015;96(Pt A):70-82.

12. Muller $S$, Scaffidi $P$, Degryse B, Bonaldi T, Ronfani L, Agresti A, et al. New EMBO members' review: the double life of HMGB1 chromatin protein: architectural factor and extracellular signal. EMBO J. 2001;20(16):4337-40.

13. Jiang W, Bell CW, Pisetsky DS. The relationship between apoptosis and high-mobility group protein 1 release from murine macrophages stimulated with lipopolysaccharide or polyinosinic-polycytidylic acid. J Immunol. 2007; 178(10):6495-503.

14. Engel T, Alves M, Sheedy C, Henshall DC. ATPergic signalling during seizures and epilepsy. Neuropharmacology. 2016;104:140-53.

15. Iori V, Maroso M, Rizzi M, lyer AM, Vertemara R, Carli M, et al. Receptor for advanced glycation Endproducts is upregulated in temporal lobe epilepsy and contributes to experimental seizures. Neurobiol Dis. 2013;58:102-14.
16. Chang ZL. Important aspects of toll-like receptors, ligands and their signaling pathways. Inflamm Res. 2010;59(10):791-808.

17. Xie J, Mendez JD, Mendezvalenzuela V, Aguilarhernandez MM. Cellular signalling of the receptor for advanced glycation end products (RAGE). Cell Signal. 2013;25(11):2185-97.

18. Balosso S, Liu J, Bianchi ME, Vezzani A. Disulfide-containing high mobility group box-1 promotes $\mathrm{N}$-methyl-D-aspartate receptor function and excitotoxicity by activating toll-like receptor 4-dependent signaling in hippocampal neurons. Antioxid Redox Signal. 2014;21(12):1726-40.

19. Lee DY, Moon J, Lee ST, Jung KH, Park DK, Yoo JS, et al. Dysregulation of long non-coding RNAs in mouse models of localization-related epilepsy. Biochem Biophys Res Commun. 2015;462(4):433-40.

20. Li YJ, Wang L, Zhang B, Gao F, Yang CM. Glycyrrhizin, an HMGB1 inhibitor, exhibits neuroprotective effects in rats after lithium-pilocarpine-induced status epilepticus. J Pharm Pharmacol. 2019;71(3):390-9.

21. Festoff BW, Sajja RK, van Dreden P, Cucullo L. HMGB1 and thrombin mediate the blood-brain barrier dysfunction acting as biomarkers of neuroinflammation and progression to neurodegeneration in Alzheimer's disease. J Neuroinflammation. 2016;13(1):194.

22. Yang Y, Cheng X, Li W, Liu M, Wang Y, Du G. Kaempferol attenuates LPSinduced striatum injury in mice involving anti-Neuroinflammation, maintaining BBB integrity, and Down-regulating the HMGB1/TLR4 pathway. Int J Mol Sci. 2019;20(3):491.

23. Chen Y, Huang XJ, Yu N, Xie Y, Zhang K, Wen F, et al. HMGB1 contributes to the expression of P-glycoprotein in mouse epileptic brain through toll-like receptor 4 and receptor for advanced glycation end products. PLoS One. 2015;10(10):e0140918.

24. Maroso M, Balosso S, Ravizza T, Liu J, Aronica E, lyer AM, et al. Toll-like receptor 4 and high-mobility group box-1 are involved in ictogenesis and can be targeted to reduce seizures. Nat Med. 2010;16(4):413-9.

25. Pankratov $Y$, Lalo U, Verkhratsky A, North RA. Vesicular release of ATP at central synapses. Pflugers Archiv: Eur J Physiol. 2006:452(5):589-97.

26. Burnstock $G$. An introduction to the roles of purinergic signalling in neurodegeneration, neuroprotection and neuroregeneration. Neuropharmacology. 2016;104:4-17.

27. Idzko M, Ferrari $D$, Eltzschig HK. Nucleotide signalling during inflammation. Nature. 2014;509(7500):310-7.

28. Alves M, Gomez-Villafuertes R, Delanty N, Farrell MA, O'Brien DF, MirasPortugal MT, et al. Expression and function of the metabotropic purinergic P2Y receptor family in experimental seizure models and patients with drugrefractory epilepsy. Epilepsia. 2017;58(9):1603-14.

29. Abbracchio MP, Burnstock G, Verkhratsky A, Zimmermann H. Purinergic signalling in the nervous system: an overview. Trends Neurosci. 2009:32(1):19-29.

30. Burnstock G. Physiology and pathophysiology of purinergic neurotransmission. Physiol Rev. 2007;87(2):659-797.

31. Jacobson KA, Muller CE. Medicinal chemistry of adenosine, P2Y and P2X receptors. Neuropharmacology. 2016;104:31-49.

32. Beamer E, Fischer W, Engel T. The ATP-gated P2X7 receptor as a target for the treatment of drug-resistant epilepsy. Front Neurosci. 2017;11:21.

33. Huang C, Chi XS, Li R, Hu X, Xu HX, Li JM, et al. Inhibition of P2X7 receptor ameliorates nuclear factor-kappa B mediated Neuroinflammation induced by status epilepticus in rat hippocampus. J Molecular Neurosci. 2017;63(2): 173-84.

34. Beamer E, Gölöncsér F, Horváth G, Bekõ K, Otrokocsi L, Koványi B, et al. Purinergic mechanisms in neuroinflammation: an update from molecules to behavior. Neuropharmacol. 2016;104:94-104.

35. McElroy PB, Liang LP, Day BJ, Patel M. Scavenging reactive oxygen species inhibits status epilepticus-induced neuroinflammation. Exp Neurol. 2017; 298(Pt A):13-22

36. Yang F, Zhao K, Zhang X, Zhang J, Xu B. ATP induces disruption of tight junction proteins via IL-1 Beta-dependent MMP-9 activation of human blood-brain barrier in vitro. Neural Plast. 2016;2016:8928530.

37. Barros-Barbosa AR, Oliveira Â, Lobo MG, Cordeiro JM, Correia-de-Sá P. Under stressful conditions activation of the ionotropic $\mathrm{P} 2 \mathrm{X} 7$ receptor differentially regulates GABA and glutamate release from nerve terminals of the rat cerebral cortex. Neurochem Int. 2018;112:81-95.

38. Iori V, Frigerio F, Vezzani A. Modulation of neuronal excitability by immune mediators in epilepsy. Curr Opin Pharmacol. 2016:26:118-23.

39. Vezzani A, Maroso M, Balosso S, Sanchez MA, Bartfai T. IL-1 receptor/toll-like receptor signaling in infection, inflammation, stress and neurodegeneration couples hyperexcitability and seizures. Brain Behav Immun. 2011;25(7):1281-9. 
40. Li T, Jia Y, Ma C, Qiu W, Wang Q, Shao X, et al. The role of the microRNA146a/complement factor $\mathrm{H} /$ interleukin-1 $\beta$-mediated inflammatory loop circuit in the perpetuate inflammation of chronic temporal lobe epilepsy. Dis Model Mech. 2018;11(3):dmm031708.

41. Balosso S, Maroso M, Sanchez-Alavez M, Ravizza T, Frasca A, Bartfai T, et al. A novel non-transcriptional pathway mediates the proconvulsive effects of interleukin-1beta. Brain : A J Neurol. 2008;131(Pt 12):3256-65.

42. Xiao Z, Peng J, Wu L, Arafat A, Yin F. The effect of IL-1 $\beta$ on synaptophysin expression and electrophysiology of hippocampal neurons through the PI3K/Akt/mTOR signaling pathway in a rat model of mesial temporal lobe epilepsy. Neurol Res. 2017;39(7):640-8.

43. Ferrari CC, Depino AM, Prada F, Muraro N, Campbell S, Podhajcer O, et al. Reversible demyelination, blood-brain barrier breakdown, and pronounced neutrophil recruitment induced by chronic IL-1 expression in the brain. Am J Pathol. 2004;165(5):1827-37.

44. Noe FM, Polascheck N, Frigerio F, Bankstahl M, Ravizza T, Marchini S, et al. Pharmacological blockade of IL-1beta/IL-1 receptor type 1 axis during epileptogenesis provides neuroprotection in two rat models of temporal lobe epilepsy. Neurobiol Dis. 2013;59:183-93.

45. Kenney-Jung DL, Vezzani A, Kahoud RJ, LaFrance-Corey RG, Ho ML, Muskardin TW, et al. Febrile infection-related epilepsy syndrome treated with anakinra. Ann Neurol. 2016;80(6):939-45.

46. Erta M, Quintana A, Hidalgo J. Interleukin-6, a major cytokine in the central nervous system. Int J Biol Sci. 2012;8(9):1254-66.

47. Gruol DL. IL-6 regulation of synaptic function in the CNS. Neuropharmacology. 2015;96(Pt A):42-54.

48. Lehtimaki KA, Keranen T, Palmio J, Rainesalo S, Saransaari P, Peltola J. Regulation of cerebrospinal fluid levels of cytokines after seizures: the role of IL-6 and glutamic acid. Eur J Neurol. 2009;16(4):e75.

49. D'Arcangelo G, Tancredi V, Onofri F, D'Antuono M, Giovedi S, Benfenati F. Interleukin-6 inhibits neurotransmitter release and the spread of excitation in the rat cerebral cortex. Eur J Neurosci. 2000;12(4):1241-52.

50. Garcia-Oscos F, Salgado H, Hall S, Thomas F, Farmer GE, Bermeo J, et al. The stress-induced cytokine interleukin- 6 decreases the inhibition/excitation ratio in the rat temporal cortex via trans-signaling. Biol Psychiatry. 2012;71(7):574-82.

51. Jun JS, Lee ST, Kim R, Chu K, Lee SK. Tocilizumab treatment for new onset refractory status epilepticus. Ann Neurol. 2018;84(6):940-5.

52. Turrin NP, Rivest $\mathrm{S}$. Innate immune reaction in response to seizures: implications for the neuropathology associated with epilepsy. Neurobiol Dis. 2004;16(2):321-34

53. Welser-Alves JV, Milner R. Microglia are the major source of TNF-alpha and TGF-beta1 in postnatal glial cultures; regulation by cytokines, lipopolysaccharide, and vitronectin. Neurochem Int. 2013;63(1):47-53.

54. Kim JE, Ryu HJ, Kang TC. P2X7 receptor activation ameliorates CA3 neuronal damage via a tumor necrosis factor-alpha-mediated pathway in the rat hippocampus following status epilepticus. J Neuroinflammation. 2011:8:62

55. van Vliet EA, Aronica E, Vezzani A, Ravizza T. Review: Neuroinflammatory pathways as treatment targets and biomarker candidates in epilepsy: emerging evidence from preclinical and clinical studies. Neuropathol Appl Neurobiol. 2018;44(1):91-111.

56. Balosso S, Ravizza T, Aronica E, Vezzani A. The dual role of TNF-alpha and its receptors in seizures. Exp Neurol. 2013;247:267-71.

57. Balosso S, Ravizza T, Perego C, Peschon J, Campbell IL, De Simoni MG, et al. Tumor necrosis factor-alpha inhibits seizures in mice via p75 receptors. Ann Neurol. 2005;57(6):804-12.

58. Bernardino L, Xapelli S, Silva AP, Jakobsen B, Poulsen FR, Oliveira CR, et al. Modulator effects of interleukin-1beta and tumor necrosis factor-alpha on AMPA-induced excitotoxicity in mouse organotypic hippocampal slice cultures. J Neurosci. 2005;25(29):6734-44.

59. Kim JE, Ryu HJ, Kang TC. Status epilepticus induces vasogenic edema via tumor necrosis factor- $a$ / endothelin-1-mediated two different pathways. PLoS One. 2013;8(9):e74458.

60. Takeuchi H, Jin S, Wang J, Zhang G, Kawanokuchi J, Kuno R, et al. Tumor necrosis factor-alpha induces neurotoxicity via glutamate release from hemichannels of activated microglia in an autocrine manner. J Biol Chem. 2006;281(30):21362-8.

61. Bezzi P, Domercq M, Brambilla L, Galli R, Schols D, De Clercq E, et al. CXCR4activated astrocyte glutamate release via TNFalpha: amplification by microglia triggers neurotoxicity. Nat Neurosci. 2001;4(7):702-10.

62. Danbolt NC. Glutamate uptake. Prog Neurobiol. 2001;65(1):1-105.
63. Xu D, Robinson AP, Ishii T, Duncan DAS, Alden TD, Goings GE, et al. Peripherally derived $T$ regulatory and $\gamma \delta T$ cells have opposing roles in the pathogenesis of intractable pediatric epilepsy. J Exp Med. 2018;215(4):116986.

64. Lagarde S, Villeneuve N, Trébuchon A, Kaphan E, Lepine A, McGonigal A, et al. Anti-tumor necrosis factor alpha therapy (adalimumab) in Rasmussen's encephalitis: an open pilot study. Epilepsia. 2016;57(6):956-66.

65. Bar-Klein G, Cacheaux LP, Kamintsky L, Prager O, Weissberg I, Schoknecht K, et al. Losartan prevents acquired epilepsy via TGF-beta signaling suppression. Ann Neurol. 2014;75(6):864-75.

66. Meyers EA, Kessler JA. TGF- $\beta$ family signaling in neural and neuronal differentiation, development, and function. Cold Spring Harb Perspect Biol. 2017:9(8):a022244

67. Li MO, Flavell RA. TGF-beta: a master of all T cell trades. Cell. 2008;134(3): 392-404.

68. Ivens S, Kaufer D, Flores LP, Bechmann I, Zumsteg D, Tomkins O, et al. TGFbeta receptor-mediated albumin uptake into astrocytes is involved in neocortical epileptogenesis. Brain : A J Neurol. 2007;130(Pt 2):535-47.

69. Rustenhoven J, Aalderink M, Scotter EL, Oldfield RL, Bergin PS, Mee EW, et al. TGF-beta1 regulates human brain pericyte inflammatory processes involved in neurovasculature function. J Neuroinflammation. 2016;13:37.

70. Perillan PR, Chen M, Potts EA, Simard JM. Transforming growth factor-beta 1 regulates Kir2.3 inward rectifier $\mathrm{K}+$ channels via phospholipase $\mathrm{C}$ and protein kinase C-delta in reactive astrocytes from adult rat brain. J Biol Chem. 2002;277(3):1974-80.

71. Levy N, Milikovsky DZ, Baranauskas G, Vinogradov E, David Y, Ketzef M, et al. Differential TGF-beta signaling in glial subsets underlies IL-6-mediated Epileptogenesis in mice. J Immunol. 2015;195(4):1713-22.

72. Musto $A E$, Samii M. Platelet-activating factor receptor antagonism targets neuroinflammation in experimental epilepsy. Epilepsia. 2011;52(3):551-61.

73. Belayev L, Khoutorova L, Atkins K, Gordon WC, Alvarez-Builla J, Bazan NG. LAU-0901, a novel platelet-activating factor antagonist, is highly neuroprotective in cerebral ischemia. Exp Neurol. 2008;214(2):253-8.

74. Boetkjaer A, Boedker M, Cui JG, Zhao Y, Lukiw WJ. Synergism in the repression of COX-2- and TNFalpha-induction in platelet activating factorstressed human neural cells. Neurosci Lett. 2007;426(1):59-63.

75. Cerri C, Caleo M, Bozzi Y. Chemokines as new inflammatory players in the pathogenesis of epilepsy. Epilepsy Res. 2017;136:77-83.

76. Choi J, Nordli DR Jr, Alden TD, DiPatri A Jr, Laux L, Kelley K, et al. Cellular injury and neuroinflammation in children with chronic intractable epilepsy. J Neuroinflammation. 2009;6:38.

77. Yao Y, Tsirka SE. Monocyte chemoattractant protein-1 and the blood-brain barrier. Cellular Molecular Life Sci. 2014;71(4):683-97.

78. van Gassen KL, Netzeband JG, de Graan PN, Gruol DL. The chemokine CCL2 modulates Ca2+ dynamics and electrophysiological properties of cultured cerebellar Purkinje neurons. Eur J Neurosci. 2005;21(11):2949-57.

79. Zhou Y, Tang H, Liu J, Dong J, Xiong H. Chemokine CCL2 modulation of neuronal excitability and synaptic transmission in rat hippocampal slices. J Neurochem. 2011;116(3):406-14.

80. Tian DS, Peng J, Murugan M, Feng LJ, Liu JL, Eyo UB, et al. Chemokine CCL2-CCR2 signaling induces neuronal cell death via STAT3 activation and IL-1 beta production after status epilepticus. J Neurosci. 2017;37(33):7878-92.

81. Boison D. When GABA fails: rundown on chemokines. Epilepsy Curr. 2014; 14(3):155-7.

82. Liu X, Yang L, Shao L, He Y, Wu G, Bao Y, et al. Endothelial Cdk5 deficit leads to the development of spontaneous epilepsy through CXCL1/CXCR2mediated reactive astrogliosis. J Exp Med. 2020;217(1):e20180992.

83. Xu T, Yu X, Deng J, Ou S, Liu X, Wang T, et al. CXCR7 regulates epileptic seizures by controlling the synaptic activity of hippocampal granule cells. Cell Death Dis. 2019;10(11):825

84. Mao LY, Ding J, Peng WF, Ma Y, Zhang YH, Fan W, et al. Interictal interleukin-17A levels are elevated and correlate with seizure severity of epilepsy patients. Epilepsia. 2013;54(9):e142-5.

85. Weidner LD, Kannan P, Mitsios N, Kang SJ, Hall MD, Theodore WH, et al. The expression of inflammatory markers and their potential influence on efflux transporters in drug-resistant mesial temporal lobe epilepsy tissue. Epilepsia. 2018;59(8):1507-17.

86. Rojas A, Jiang J, Ganesh T, Yang MS, Lelutiu N, Gueorguieva P, et al. Cyclooxygenase-2 in epilepsy. Epilepsia. 2014;55(1):17-25.

87. Vezzani A, French J, Bartfai T, Baram TZ. The role of inflammation in epilepsy. Nat Rev Neurol. 2011;7(1):31-40. 
88. Choi SH, Aid S, Bosetti F. The distinct roles of cyclooxygenase-1 and -2 in neuroinflammation: implications for translational research. Trends Pharmaco Sci. 2009;30(4):174-81.

89. Tanaka S, Nakamura T, Sumitani K, Takahashi F, Konishi R, Itano T, et al. Stage- and region-specific cyclooxygenase expression and effects of a selective COX-1 inhibitor in the mouse amygdala kindling model. Neurosci Res. 2009;65(1):79-87.

90. FitzGerald GA. COX-2 and beyond: approaches to prostaglandin inhibition in human disease. Nat Rev Drug Discov. 2003;2(11):879-90.

91. Dudek FE. Mechanisms of seizure-induced inflammation of the brain: many possible roles for neuronal COX-2. Epilepsy Curr. 2012;12(3):115-7.

92. Chen C, Bazan NG. Endogenous PGE2 regulates membrane excitability and synaptic transmission in hippocampal CA1 pyramidal neurons. J Neurophysiol. 2005;93(2):929-41.

93. Takemiya T, Maehara M, Matsumura K, Yasuda S, Sugiura H, Yamagata K. Prostaglandin E2 produced by late induced COX-2 stimulates hippocampal neuron loss after seizure in the CA3 region. Neurosci Res. 2006;56(1):103-10.

94. Yagami T, Koma H, Yamamoto Y. Pathophysiological roles of cyclooxygenases and prostaglandins in the central nervous system. Mol Neurobiol. 2016;53(7):4754-71.

95. Gobbo OL, O'Mara SM. Post-treatment, but not pre-treatment, with the selective cyclooxygenase-2 inhibitor celecoxib markedly enhances functional recovery from kainic acid-induced neurodegeneration. Neuroscience. 2004;125(2):317-27.

96. Kim HJ, Chung Jl, Lee SH, Jung YS, Moon CH, Baik E. Involvement of endogenous prostaglandin F2alpha on kainic acid-induced seizure activity through FP receptor: the mechanism of proconvulsant effects of COX-2 inhibitors. Brain Res. 2008;1193:153-61.

97. Jeong KH, Kim JY, Choi YS, Lee MY, Kim SY. Influence of aspirin on pilocarpine-induced epilepsy in mice. Kor J Physiol Pharmacol. 2013;17(1): $15-21$.

98. Trandafir CC, Pouliot WA, Dudek FE, Ekstrand JJ. Co-administration of subtherapeutic diazepam enhances neuroprotective effect of COX-2 inhibitor, NS-398, after lithium pilocarpine-induced status epilepticus. Neuroscience. 2015;284:601-10.

99. Ma L, Cui XL, Wang Y, Li XW, Yang F, Wei D, et al. Aspirin attenuates spontaneous recurrent seizures and inhibits hippocampal neuronal loss, mossy fiber sprouting and aberrant neurogenesis following pilocarpineinduced status epilepticus in rats. Brain Res. 2012;1469:103-13.

100. Zhu K, Hu M, Yuan B, Liu JX, Liu Y. Aspirin attenuates spontaneous recurrent seizures in the chronically epileptic mice. Neurol Res. 2017;39(8):744-57.

101. Lo MW, Woodruff TM. Complement: bridging the innate and adaptive immune systems in sterile inflammation. J Leukoc Biol. 2020;108(1):339-51.

102. Kim SY, Son M, Lee SE, Park IH, Kwak MS, Han M, et al. High-mobility group box 1-induced complement activation causes sterile inflammation. Front Immunol. 2018;9:705

103. Presumey J, Bialas AR, Carroll MC. Complement system in neural synapse elimination in development and disease. Adv Immunol. 2017;135:53-79.

104. Wyatt SK, Witt T, Barbaro NM, Cohen-Gadol AA, Brewster AL. Enhanced classical complement pathway activation and altered phagocytosis signaling molecules in human epilepsy. Exp Neurol. 2017;295:184-93.

105. Wu F, Zou Q, Ding X, Shi D, Zhu X, Hu W, et al. Complement component C3a plays a critical role in endothelial activation and leukocyte recruitment into the brain. J Neuroinflammation. 2016;13:23.

106. Fabene PF, Navarro Mora G, Martinello M, Rossi B, Merigo F, Ottoboni L, et al. A role for leukocyte-endothelial adhesion mechanisms in epilepsy. Nat Med. 2008;14(12):1377-83.

107. Kudin AP, Zsurka G, Elger CE, Kunz WS. Mitochondrial involvement in temporal lobe epilepsy. Exp Neurol. 2009;218(2):326-32.

108. Zsurka G, Kunz WS. Mitochondrial dysfunction and seizures: the neuronal energy crisis. Lancet Neurol. 2015;14(9):956-66.

109. Vezzani A, Balosso S, Ravizza T. Neuroinflammatory pathways as treatment targets and biomarkers in epilepsy. Nat Rev Neurol. 2019;15(8):459-72.

110. Morgan MJ, Liu ZG. Crosstalk of reactive oxygen species and NF-kappaB signaling. Cell Res. 2011;21(1):103-15.

111. Ye J, Jiang Z, Chen X, Liu M, Li J, Liu N. The role of autophagy in proinflammatory responses of microglia activation via mitochondrial reactive oxygen species in vitro. J Neurochem. 2017;142(2):215-30.

112. Russo E, Citraro R, Constanti A, De Sarro G. The mTOR signaling pathway in the brain: focus on epilepsy and epileptogenesis. Mol Neurobiol. 2012;46(3): 662-81.
113. Snowball A, Schorge S. Changing channels in pain and epilepsy: exploiting ion channel gene therapy for disorders of neuronal hyperexcitability. FEBS Lett. 2015;589(14):1620-34

114. Hodges SL, Lugo JN. Therapeutic role of targeting mTOR signaling and neuroinflammation in epilepsy. Epilepsy Res. 2020;161:106282.

115. van Vliet EA, Otte WM, Wadman WJ, Aronica E, Kooij G, de Vries HE, et al. Blood-brain barrier leakage after status epilepticus in rapamycin-treated rats II: potential mechanisms. Epilepsia. 2016;57(1):70-8.

116. Wang $X$, Sha $L$, Sun $N$, Shen $Y, X u$ Q. Deletion of mTOR in reactive astrocytes suppresses chronic seizures in a mouse model of temporal lobe epilepsy. Mol Neurobiol. 2017;54(1):175-87.

117. Yang MT, Lin YC, Ho WH, Liu CL, Lee WT. Everolimus is better than rapamycin in attenuating neuroinflammation in kainic acid-induced seizures. J Neuroinflammation. 2017;14(1):15.

118. Drion CM, van Scheppingen J, Arena A, Geijtenbeek KW, Kooijman L, van Vliet EA, et al. Effects of rapamycin and curcumin on inflammation and oxidative stress in vitro and in vivo - in search of potential antiepileptogenic strategies for temporal lobe epilepsy. J Neuroinflammation. 2018;15(1):212.

119. Norris GT, Kipnis J. Immune cells and CNS physiology: microglia and beyond. J Exp Med. 2019;216(1):60-70.

120. Benson MJ, Manzanero S, Borges K. Complex alterations in microglial M1/ M2 markers during the development of epilepsy in two mouse models. Epilepsia. 2015;56(6):895-905.

121. Eyo UB, Peng J, Swiatkowski P, Mukherjee A, Bispo A, Wu LJ. Neuronal hyperactivity recruits microglial processes via neuronal NMDA receptors and microglial P2Y12 receptors after status epilepticus. J Neurosci. 2014;34(32): 10528-40.

122. Mo M, Eyo UB, Xie M, Peng J, Bosco DB, Umpierre AD, et al. Microglial $P 2 Y 12$ receptor regulates seizure-induced neurogenesis and immature neuronal projections. J Neurosci. 2019;39(47):9453-64.

123. Matsuda T, Murao N, Katano Y, Juliandi B, Kohyama J, Akira S, et al. TLRg signalling in microglia attenuates seizure-induced aberrant neurogenesis in the adult hippocampus. Nat Commun. 2015;6:6514.

124. Jakubs K, Nanobashvili A, Bonde S, Ekdahl CT, Kokaia Z, Kokaia M, et al. Environment matters: synaptic properties of neurons born in the epileptic adult brain develop to reduce excitability. Neuron. 2006;52(6):1047-59.

125. Eyo UB, Murugan M, Wu LJ. Microglia-neuron communication in epilepsy. Glia. 2017;65(1):5-18

126. Vinet J, Weering HR, Heinrich A, Kalin RE, Wegner A, Brouwer N, et al. Neuroprotective function for ramified microglia in hippocampal excitotoxicity. J Neuroinflammation. 2012;9:27.

127. Ben Haim L, Rowitch DH. Functional diversity of astrocytes in neural circuit regulation. Nat Rev Neurosci. 2017;18(1):31-41.

128. Strokin M, Sergeeva M, Reiser G. Proinflammatory treatment of astrocytes with lipopolysaccharide results in augmented Ca2+ signaling through increased expression of via phospholipase A2 (iPLA2). Am J Physiol Cell Physiol. 2011;300(3):C542-9.

129. Zhu X, Dong J, Han B, Huang R, Zhang A, Xia Z, et al. Neuronal nitric oxide synthase contributes to PTZ kindling epilepsy-induced hippocampal endoplasmic reticulum stress and oxidative damage. Front Cell Neurosci. 2017;11:377.

130. Shim S, Shuman M, Duncan E. An emerging role of cGMP in the treatment of schizophrenia: a review. Schizophr Res. 2016;170(1):226-31.

131. Toth AB, Hori $K$, Novakovic MM, Bernstein NG, Lambot L, Prakriya M. CRAC channels regulate astrocyte $\mathrm{Ca} 2+$ signaling and gliotransmitter release to modulate hippocampal GABAergic transmission. Sci Signal. 2019;12(582): eaaw5450.

132. Ravizza T, Boer K, Redeker S, Spliet WG, van Rijen PC, Troost D, et al. The IL1 beta system in epilepsy-associated malformations of cortical development. Neurobiol Dis. 2006;24(1):128-43.

133. Librizzi L, Noe F, Vezzani A, de Curtis M, Ravizza T. Seizure-induced brainborne inflammation sustains seizure recurrence and blood-brain barrier damage. Ann Neurol. 2012;72(1):82-90.

134. Rempe RG, Hartz AMS, Soldner ELB, Sokola BS, Alluri SR, Abner EL, et al. Matrix metalloproteinase-mediated blood-brain barrier dysfunction in epilepsy. J Neurosci. 2018;38(18):4301-15.

135. David Y, Cacheaux LP, Ivens S, Lapilover E, Heinemann U, Kaufer D, et al. Astrocytic dysfunction in epileptogenesis: consequence of altered potassium and glutamate homeostasis? J Neurosci. 2009; 29(34):10588-99. 
136. Heinemann U, Kaufer D, Friedman A. Blood-brain barrier dysfunction, TGFbeta signaling, and astrocyte dysfunction in epilepsy. Glia. 2012;60(8): $1251-7$

137. Djukic B, Casper KB, Philpot BD, Chin LS, McCarthy KD. Conditional knockout of Kir4.1 leads to glial membrane depolarization, inhibition of potassium and glutamate uptake, and enhanced short-term synaptic potentiation. J Neurosci. 2007;27(42):11354-65.

138. Malik AR, Willnow TE. Excitatory amino acid transporters in physiology and disorders of the central nervous system. Int J Mol Sci. 2019;20(22):5671.

139. Campbell SL, Hablitz JJ. Decreased glutamate transport enhances excitability in a rat model of cortical dysplasia. Neurobiol Dis. 2008;32(2):254-61.

140. Henneberger C, Steinhauser C. Astrocytic TLR4 at the crossroads of inflammation and seizure susceptibility. J Cell Biol. 2016;215(5):607-9.

141. Bauer J, Becker AJ, Elyaman W, Peltola J, Ruegg S, Titulaer MJ, et al. Innate and adaptive immunity in human epilepsies. Epilepsia. 2017;58(Suppl 3):5768.

142. Xu D, Robinson AP, Ishii T, Duncan DS, Alden TD, Goings GE, et al. Peripherally derived $T$ regulatory and gammadelta T cells have opposing roles in the pathogenesis of intractable pediatric epilepsy. J Exp Med. 2018; 215(4):1169-86.

143. Xia J, Wang H, Zhang Q, Han Z. Modulation of P2X Purinoceptor 3 (P2X3) in Pentylenetetrazole-induced kindling epilepsy in rats. Med Sci Monitor. 2018; 24:6165-77.

144. Burnstock G. Purinergic signalling and disorders of the central nervous system. Nat Rev Drug Discov. 2008;7(7):575-90.

145. Alves M, De Diego Garcia L, Conte G, Jimenez-Mateos EM, D'Orsi B, SanzRodriguez A, et al. Context-specific switch from anti- to pro-epileptogenic function of the P2Y receptor in experimental epilepsy. J Neurosci. 2019; 39(27):5377-92.

146. Hanke ML, Kielian T. Toll-like receptors in health and disease in the brain: mechanisms and therapeutic potential. Clin Sci (Lond). 2011;121(9):367-87.

147. Vezzani A, Aronica E, Mazarati A, Pittman QJ. Epilepsy and brain inflammation. Exp Neurol. 2013;244:11-21.

148. Gross A, Benninger F, Madar R, Illouz T, Griffioen K, Steiner I, et al. Toll-like receptor 3 deficiency decreases epileptogenesis in a pilocarpine model of SE-induced epilepsy in mice. Epilepsia. 2017;58(4):586-96.

149. Dombkowski AA, Cukovic D, Bagla S, Jones M, Caruso JA, Chugani HT, et al. TLR7 activation in epilepsy of tuberous sclerosis complex. Inflamm Res. 2019;68(12):993-8.

150. Stanimirovic DB, Friedman A. Pathophysiology of the neurovascular unit: disease cause or consequence? J Cereb Blood Flow Metab. 2012;32(7):120721.

151. Morin-Brureau M, Lebrun A, Rousset MC, Fagni L, Bockaert J, de Bock F, et al. Epileptiform activity induces vascular remodeling and zonula occludens 1 downregulation in organotypic hippocampal cultures: role of VEGF signaling pathways. J Neurosci. 2011;31(29):10677-88.

152. Serrano GE, Lelutiu N, Rojas A, Cochi S, Shaw R, Makinson CD, et al. Ablation of cyclooxygenase- 2 in forebrain neurons is neuroprotective and dampens brain inflammation after status epilepticus. J Neurosci. 2011;31(42):14850-60.

153. van Vliet EA, Zibell G, Pekcec A, Schlichtiger J, Edelbroek PM, Holtman L, et al. COX-2 inhibition controls P-glycoprotein expression and promotes brain delivery of phenytoin in chronic epileptic rats. Neuropharmacology. 2010;58(2):404-12.

154. Marchi N, Fan Q, Ghosh C, Fazio V, Bertolini F, Betto G, et al. Antagonism of peripheral inflammation reduces the severity of status epilepticus. Neurobiol Dis. 2009;33(2):171-81.

155. Marchi N, Angelov L, Masaryk T, Fazio V, Granata T, Hernandez N, et al. Seizure-promoting effect of blood-brain barrier disruption. Epilepsia. 2007; 48(4):732-42.

156. Frigerio F, Frasca A, Weissberg I, Parrella S, Friedman A, Vezzani A, et al. Long-lasting pro-ictogenic effects induced in vivo by rat brain exposure to serum albumin in the absence of concomitant pathology. Epilepsia. 2012; 53(11):1887-97.

157. Michalak Z, Lebrun A, Di Miceli M, Rousset MC, Crespel A, Coubes P, et al. IgG leakage may contribute to neuronal dysfunction in drug-refractory epilepsies with blood-brain barrier disruption. J Neuropathol Exp Neurol. 2012;71(9):826-38

158. Webster KM, Sun M, Crack P, O'Brien TJ, Shultz SR, Semple BD. Inflammation in epileptogenesis after traumatic brain injury. J Neuroinflammation. 2017 14(1):10
159. Webster KM, Shultz SR, Ozturk E, Dill LK, Sun M, Casillas-Espinosa P, et al. Targeting high-mobility group box protein 1 (HMGB1) in pediatric traumatic brain injury: chronic neuroinflammatory, behavioral, and epileptogenic consequences. Exp Neurol. 2019;320:112979.

160. Semple BD, O'Brien TJ, Gimlin K, Wright DK, Kim SE, Casillas-Espinosa PM, et al. Interleukin-1 receptor in seizure susceptibility after traumatic injury to the pediatric brain. J Neurosci. 2017;37(33):7864-77.

161. Therajaran P, Hamilton JA, O'Brien TJ, Jones NC, Ali I. Microglial polarization in posttraumatic epilepsy: potential mechanism and treatment opportunity. Epilepsia. 2020;61(2):203-15.

162. Chen M, Edwards SR, Reutens DC. Complement in the development of post-traumatic epilepsy: prospects for drug repurposing. J Neurotrauma. 2020;37(5):692-705

163. Rana A, Musto AE. The role of inflammation in the development of epilepsy. J Neuroinflammation. 2018;15(1):144.

164. Dadas A, Janigro D. Breakdown of blood brain barrier as a mechanism of post-traumatic epilepsy. Neurobiol Dis. 2019;123:20-6.

165. Yang H, Rajah G, Guo A, Wang Y, Wang Q. Pathogenesis of epileptic seizures and epilepsy after stroke. Neurol Res. 2018:40(6):426-32.

166. Bronisz E, Kurkowska-Jastrzębska I. Matrix metalloproteinase 9 in epilepsy: the role of Neuroinflammation in seizure development. Mediators Inflamm. 2016;2016:7369020.

167. Feyissa AM, Hasan TF, Meschia JF. Stroke-related epilepsy. Eur J Neurol. 2019;26(1):18-e13

168. Claassen J, Albers D, Schmidt JM, De Marchis GM, Pugin D, Falo CM, et al. Nonconvulsive seizures in subarachnoid hemorrhage link inflammation and outcome. Ann Neurol. 2014;75(5):771-81.

169. Chaudhry SR, Stoffelwagner B, Kinfe TM, Guresir E, Vatter H, Dietrich D, et al. Elevated systemic IL-6 levels in patients with aneurysmal subarachnoid hemorrhage is an unspecific marker for post-SAH complications. Int J Mol Sci. 2017;18(12):2580.

170. Stone TJ, Rowell R, Jayasekera BAP, Cunningham MO, Jacques TS. Review: molecular characteristics of long-term epilepsy-associated tumours (LEATs) and mechanisms for tumour-related epilepsy (TRE). Neuropathol Appl Neurobiol. 2018;44(1):56-69.

171. Serafini A, Lukas RV, VanHaerents S, Warnke $P$, Tao JX, Rose $S$, et al. Paraneoplastic epilepsy. Epilepsy Behav. 2016;61:51-8.

172. Geis C, Planagumà J, Carreño M, Graus F, Dalmau J. Autoimmune seizures and epilepsy. J Clin Invest. 2019;129(3):926-40.

173. Lim SH, Park E, You B, Jung Y, Park AR, Park SG, et al. Neuronal synapse formation induced by microglia and interleukin 10. PLoS One. 2013;8(11): e81218.

174. Wang JB, Li H, Wang LL, Liang HD, Zhao L, Dong J. Role of IL-1ß, IL-6, IL-8 and IFN- $\gamma$ in pathogenesis of central nervous system neuropsychiatric systemic lupus erythematous. Int J Clin Exp Med. 2015;8(9):16658-63.

175. Yorulmaz H, Kaptan E, Seker FB, Oztas B. Type 1 diabetes exacerbates bloodbrain barrier alterations during experimental epileptic seizures in an animal model. Cell Biochem Funct. 2015;33(5):285-92.

176. Vincent A, Crino PB. Systemic and neurologic autoimmune disorders associated with seizures or epilepsy. Epilepsia. 2011;52:12-7.

177. Beghi E, Shorvon S. Antiepileptic drugs and the immune system. Epilepsia. 2011;52(Suppl 3):40-4.

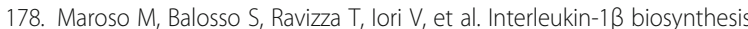
inhibition reduces acute seizures and drug resistant chronic epileptic activity in mice. Neurotherapeutics. 2011;8(2):304-15.

179. Ravizza T, Noé F, Zardoni D, Vaghi V, Sifringer M, Vezzani A. Interleukin converting enzyme inhibition impairs kindling epileptogenesis in rats by blocking astrocytic IL-1 beta production. Neurobiol Dis. 2008;31(3):327-33.

180. M B, SI J, RH L, E P, T T, HS W. Progress report on new antiepileptic drugs: a summary of the eleventh EILAT conference (EILAT XI). Epilepsy Res. 2013; 103(1):2-30.

181. Jyonouchi H, Geng L. Intractable epilepsy (IE) and responses to Anakinra, a human recombinant IL-1 receptor agonist (IL-1ra): case reports. J Clin Cellular Immunol. 2016;7:456

182. Zhao J, Wang Y, Xu C, Liu K, Wang Y, Chen L, et al. Therapeutic potential of an anti-high mobility group box-1 monoclonal antibody in epilepsy. Brain Behav Immun. 2017;64:308-19.

183. Tu B, Bazan NG. Hippocampal kindling epileptogenesis upregulates neuronal cyclooxygenase-2 expression in neocortex. Exp Neurol. 2003; 179(2):167-75. 
184. Godfred RM, Parikh MS, Haltiner AM, Caylor LM, Sepkuty JP, Doherty MJ. Does aspirin use make it harder to collect seizures during elective videoEEG telemetry? Epilepsy Behavior. 2013;27(1):115-7.

185. Lance El, Sreenivasan AK, Zabel TA, Kossoff EH, Comi AM. Aspirin use in Sturge-weber syndrome: side effects and clinical outcomes. J Child Neurol. 2013;28(2):213-8.

186. Benson MJ, Thomas NK, Talwar S, Hodson MP, Lynch JW, Woodruff TM, et al. A novel anticonvulsant mechanism via inhibition of complement receptor C5ar1 in murine epilepsy models. Neurobiol Dis. 2015;76:87-97.

187. Nowak M, Strzelczyk A, Reif PS, Schorlemmer K, Bauer S, Norwood BA, et al. Minocycline as potent anticonvulsant in a patient with astrocytoma and drug resistant epilepsy. Seizure J Brit Epilepsy Assoc. 2012;21(3):227-8.

Ready to submit your research? Choose BMC and benefit from:

- fast, convenient online submission

- thorough peer review by experienced researchers in your field

- rapid publication on acceptance

- support for research data, including large and complex data types

- gold Open Access which fosters wider collaboration and increased citations

- maximum visibility for your research: over $100 \mathrm{M}$ website views per year

At BMC, research is always in progress.

Learn more biomedcentral.com/submissions 